\title{
The Effectiveness of Currency Intervention in a Commodity-Exporter: Evidence from Mongolia
}

\section{CAMA Working Paper 31/2020 March 2020}

\section{Victor Pontines}

The South East Asian Central Banks (SEACEN) Research and Training Centre Globalization Institute, Federal Reserve Bank of Dallas

Centre for Applied Macroeconomic Analysis, ANU

\section{Davaajargal Luvsannyam}

Research and Statistics Department, Bank of Mongolia

\section{Enkhjin Atarbaatar}

Reserve Management and Financial Markets Department, Bank of Mongolia

\section{Ulziikhutag Munkhtsetseg}

Economic Research and Training Institute, Bank of Mongolia

\section{Abstract}

Although EME central banks actively intervene in currency markets, there is a longrunning debate as to its effectiveness in affecting exchange rates. In this study, we use unique daily data on currency interventions in Mongolia to analyze the impact of these interventions on the changes in the MNT/USD exchange rate. The results indicate that currency intervention is effective in Mongolia, although it differs in certain ways. Currency sales are effective in moving changes in the MNT/USD in the correct direction, especially when carried out in larger amounts and when implemented frequently. This effect can last from one to three weeks, although we find the magnitude of the daily effect to be relatively small. We do not find evidence, however, that currency purchases are effective. These findings are comparable to the existing literature on the effectiveness of intervention in EMEs. 


\section{Keywords}

Currency intervention, exchange rate, treatment effect, causal effect, local projection, Mongolia

\section{JEL Classification}

C14, C32, E58, F31

\section{Address for correspondence:}

(E) cama.admin@anu.edu.au

ISSN 2206-0332

The Centre for Applied Macroeconomic Analysis in the Crawford School of Public Policy has been established to build strong links between professional macroeconomists. It provides a forum for quality macroeconomic research and discussion of policy issues between academia, government and the private sector.

The Crawford School of Public Policy is the Australian National University's public policy school, serving and influencing Australia, Asia and the Pacific through advanced policy research, graduate and executive education, and policy impact. 


\title{
The Effectiveness of Currency Intervention in a Commodity-Exporter: Evidence from Mongolia
}

\author{
By \\ Victor Pontines ${ }^{\mathrm{a}, \mathrm{b}, \mathrm{c}}$, Davaajargal Luvsannyam ${ }^{\mathrm{d}}$, Enkhjin Atarbaatar ${ }^{\mathrm{e}}$, \\ Ulziikhutag Munkhtsetseg ${ }^{f}$
}

\begin{abstract}
Although EME central banks actively intervene in currency markets, there is a longrunning debate as to its effectiveness in affecting exchange rates. In this study, we use unique daily data on currency interventions in Mongolia to analyze the impact of these interventions on the changes in the MNT/USD exchange rate. The results indicate that currency intervention is effective in Mongolia, although it differs in certain ways. Currency sales are effective in moving changes in the MNT/USD in the correct direction, especially when carried out in larger amounts and when implemented frequently. This effect can last from one to three weeks, although we find the magnitude of the daily effect to be relatively small. We do not find evidence, however, that currency purchases are effective. These findings are comparable to the existing literature on the effectiveness of intervention in EMEs.
\end{abstract}

JEL Codes: C14, C32, E58, F31

Keywords: Currency intervention, exchange rate, treatment effect, causal effect, local projection, Mongolia

a The South East Asian Central Banks (SEACEN) Research and Training Centre, Kuala Lumpur, Malaysia.

b Centre for Applied Macroeconomic Analysis (CAMA), Australian National University (ANU), Canberra, Australia.

c Globalization Institute, Federal Reserve Bank of Dallas, Dallas, Texas, USA.

Email: vpontines@seacen.org

${ }^{d}$ Research and Statistics Department, Bank of Mongolia, Ulaanbaatar, Mongolia.

Email: davaajargal@mongolbank.mn

e Reserve Management and Financial Markets Department, Bank of Mongolia, Ulaanbaatar,

Mongolia. Email: enkhjin@mongolbank.mn

${ }^{\mathrm{f}}$ Economic Research and Training Institute, Bank of Mongolia, Ulaanbaatar, Mongolia.

Email: ulziikhutag.m@mongolbank.mn

The views expressed herein are solely those of the authors and do not necessarily reflect the views of the Bank of Mongolia, The SEACEN Centre, or SEACEN member central banks/monetary authorities. 


\section{Introduction}

Foreign exchange interventions (currency interventions from hereon), either the sales or purchases of foreign currency assets, which are typically in US dollars (USD from hereon) are aimed at affecting the level and/or the volatility of a country's exchange rate. According to Domanski, et al. (2016) and BIS (2019), since the Great Financial Crisis (GFC from hereon), currency interventions are more of an emerging market economy (EME from hereon) phenomenon with the monetary authorities in these economies having been more active in the use of such a tool. This is understandable in light of the shifting tides in foreign exchange market conditions experienced by these economies since the GFC, from the resulting appreciation pressures due to capital inflow surges and commodity booms emanating from depreciation pressures brought about by the tightening of global liquidity conditions and falling commodity prices (Domanski, et al., 2016). The extensive use of currency interventions in recent years by EMEs is also partly a reflection of the structural features inherent in most of these economies where excessive exchange rate fluctuations mainly due to thin foreign exchange markets and domination by a small number of agents, can have large and adverse effects on the real side of the economy (Disyatat and Galati, 2007).

Active use of currency interventions in practice, however, does not necessarily translate into its effectiveness in terms of achieving the desired objective of impacting the exchange rate. For instance, studies that use available daily data on currency interventions, the most commonly used data frequency for these studies, have mostly found that for developed economies, currency interventions have either no effect on the level of the exchange rate or can even increase exchange rate volatility (e.g., Bailie and Osterberg, 1997; Dominguez, 1998; Edison et al., 2006; Broto, 2013). Also, the survey papers of Edison (1993), Sarno and Taylor (2001), and Villamizar-Villegas and Perez-Reyna (2017) concluded the lack of a firm relationship between currency interventions and exchange rates in advanced economies. Somewhat contrasting views were provided by Dominguez and Frankel (1993), Fatum and Hutchison (1999), Fatum and Hutchison (2006), Fatum and Hutchison (2010).

The abundance of evidence on the effectiveness of currency interventions for advanced economies as opposed to EMEs is due to data limitations. The main reason being that very few EMEs publish their daily currency interventions. Among the EMEs, a few of the Latin American countries make their data available, which then explains the small number of country studies assessing the effectiveness of currency interventions for these group of economies. Chamon et al., (2019) in their contribution to a book-length treatment on the same topic for Latin American 
economies, make the observation that there is still no consensus on the effectiveness of currency intervention for this group of economies. ${ }^{1}$ Similar observations can also be made to findings outside of Latin American economies, for which evidence is relatively fewer. For example, using published data from the central bank of Turkey, Akinci (2006) and Onder and Villamizar-Villegas (2018) both found that currency interventions have been effective under certain conditions. Disyatat and Galati (2007), using official statistics from the Czech National Bank on currency interventions, found that interventions had weak effects on the spot rate, but no effect at all on exchange rate volatility. Also using official statistics from the Czech National Bank, Gersl and Holub (2006) found less favorable results in which interventions did not have any impact on the spot exchange rate, and a slight increase in its volatility. Fry-McKibbin and Wanaguru (2013), using official statistics on currency interventions from the Central Bank of Sri Lanka, found that interventions were effective, albeit in different ways.

Even if data on currency intervention is available, the next major challenge is the method by which the problem of endogeneity between currency interventions and exchange rates can be surmounted. There are two sources of endogeneity in this literature, which render the task of isolating the causal effect of currency interventions on the exchange rate complicated. These two threats to identification are simultaneity and self-selection bias. With regards to the former, the two-way causation between currency interventions and exchange rates complicates causality because while our main aim is to uncover the effect of intervention on the exchange rate, the monetary authorities may also be prompted to intervene when the exchange rate moves in a contrary direction. Thus, failing to control for the reverse causation renders our estimates of the effects of currency intervention on the exchange rate inconsistent. With regards to the latter, the decision to intervene by monetary authorities is not a random occurrence. The bias occurs because rather than having the amounts of official interventions determined upon them as would be the case in a randomly controlled experiment, the decision to intervene is influenced by various observed variables (also known as "confounding factors"). Because of this, it is then necessary to first model the selection decision by the monetary authorities as a function of observed confounders, which in our case is achieved by the estimation of an intervention reaction function.

Another challenge arises because currency interventions are done only intermittently, such that there is a substantial number of observations within the sample that take on zero values. Obviously, using a linear approach such as ordinary

\footnotetext{
${ }^{1}$ Hutchison (2003) and Menkhoff (2013) in earlier surveys devoted to EMEs, in general, also made the same conclusion.
} 
least squares is not suitable. Because of all these complications, a number of studies have resorted to a two-stage instrumental variable approach, based on estimates of the central bank intervention reaction function, but without resorting to ordinary least squares estimation (e.g., Disyatat and Galati, 2007; Catalán-Herrera, 2016; Echavarria, et al. 2017; Villamizar-Villegas, 2016; Onder and Villamizar-Villegas, 2018; Ordoñez-Callamand et al., 2018; Pontines, 2018). ${ }^{2}$

Using a unique dataset on daily currency interventions and a recently introduced method designed to estimate causal effects in time-series data, this study examines the effectiveness of currency interventions on the exchange rate based on the recent experience of Mongolia. Mongolia provides an interesting case study because of what the country went through during the recent commodity price boom and bust. Typical of a commodity-exporter, the country's fundamental economic problems are its lack of diversification and its proclivity to boom-bust cycles. Given the extent of its mineral endowments, Mongolia is and will remain a mining economy for many decades to come. Because of the country's narrow economic base, it is highly vulnerable to external shocks, namely commodity price fluctuations and volatility in FDI, and the lack of diversification makes the economy prone to repeated boom-bust cycles. Like many other commodity exporters, it tends to spend excessively in good times, when prices are high, and does not save enough during bad times, when extreme cuts in spending are required due to lack of buffers. Capital inflows played an important role in financing investment and external deficits, and higher commodity prices supported external balances and growth outcomes. But large capital flows and volatile commodity prices have led to greater macroeconomic volatility, real exchange rate appreciation, reduced external competitiveness and the build-up of balance sheet vulnerabilities. Although Mongolia's fiscal framework is designed to prevent such procyclicality, it has been essentially set aside in recent years. Against this backdrop, this then makes currency intervention such an important macroeconomic policy instrument for the authorities in Mongolia.

We use a recent approach that borrows from the potential outcomes literature of micro-econometrics which transfers naturally into a time-series context in terms of determining the effectiveness of a policy through the estimation of the so-called average treatment or causal effect. Angrist, Jorda and Kuersteiner (2018) (AJK from hereon) developed a semiparametric time-series method to estimate the causal effect of US monetary policy on certain macroeconomic aggregates. AJK first adopted the propensity score framework to model the probability of US federal funds rate target

${ }^{2}$ Fratzscher, et al. (2019) provide a comprehensive discussion on the methods that can be utilized to address the problem of endogeneity when assessing the effectiveness of currency interventions on exchange rates. 
changes via multinomial or ordered treatment. The resulting set of conditional distributions defines a function, which they referred to as the policy propensity score. Once these scores are obtained, AJK use a local linear projection type estimator to measure the average effect of policy changes on future values of the macroeconomic aggregates or so-called outcome variables (inflation, industrial production, and unemployment), in combination with using inverse probability weights calculated from the propensity scores. The use of inverse propensity weights relates to the wellknown micro-econometric treatment literature which uses such weighting to adjust for non-random samples.

We follow AJK and, in our specific context, we obtain an estimate of the average treatment or causal effect of currency interventions on the exchange rate. This marks the first time that this approach is applied to examine the issue of the effectiveness of currency intervention in an emerging economy context. One caveat, however, regarding any study on the effectiveness of currency interventions is that such interventions are typically accompanied by other policy measures such as monetary policy. For instance, typical of an EME, during times of high volatility in domestic currency markets, it is the case that currency sales are accompanied by an increase in the policy rate and/or the imposition of higher reserve requirement on foreign currency. Thus, the finding, if any, of an effect of currency intervention on the exchange rate may be misleading if the effects of such other policies are not sufficiently controlled. ${ }^{3}$ In the specific case of Mongolia, apart from currency interventions, the main levers of monetary policy are the policy rate as well as domestic and foreign-exchange reserve requirements, which makes this important caveat very crucial in our study.

Because of this, we deviate slightly from AJK on how we implement the identification in our case of the "unanticipated currency intervention". ${ }^{4}$ Specifically, after obtaining the policy function through the policy propensity score as in AJK, we are able to conduct in a way similar to a doubly-robust estimation of removing from the exchange rate the influence of the other instruments of monetary policy. ${ }^{5}$

3 In various estimations, Fratzscher, et al. (2019), Echavarria, et al. (2017), VillamizarVillegas (2016), Onder and Villamizar-Villegas (2018), Ordoñez-Callamand et al. (2018), Pontines (2018) acknowledged and controlled for the effects of monetary policy.

${ }^{4}$ The term is in reference to the popular vernacular of empirical macroeconomics of the effects of "unanticipated monetary policy" (AJK, 2018).

${ }^{5}$ See, for instance, Lunceford and Davidian (2004) and Glynn and Quinn (2010) which introduced the framework of doubly-robust estimation in the micro-econometric treatment effect literature. While, Jorda and Taylor (2015) adopted it to examine the average treatment effect of fiscal policy using panel-data. 
We are able to conduct this step in our investigation because we also have unique daily data on the target policy rate as well as domestic and foreign-exchange reserve requirements in Mongolia. Once this extra step is done, we can then use local linear projection type estimators to measure the average effect of currency intervention on the future values of our outcome variable, i.e., the changes in the Mongolian tugrik per USD (MNT/USD from hereon), combined with using inverse probability weights calculated from the propensity scores.

The results indicate that currency intervention is effective in Mongolia, although it differs in certain ways. Currency sales are effective in moving changes in the MNT/USD in the correct direction, especially when carried out in larger amounts and when implemented frequently. It also appears in our results that this short-run effectiveness can last from one to three weeks, although we find the magnitude of the daily effect to be relatively small. We do not find support, however, that currency purchases are effective, due albeit to the nature of the sample period that we examine which is by far dominated by currency sales. Overall, though, we note that these findings are quite comparable to the extant literature on the effectiveness of interventions in EMEs. The paper is structured as follows. The next section presents a discussion of the existing empirical evidence on the effectiveness of currency intervention in EMEs. The third section provides a description of the institutional details of currency interventions in Mongolia as well as the currency intervention data. The fourth section discusses the empirical strategy employed in the paper. The fifth section presents the empirical results and the battery of robustness tests. The fifth section concludes.

\section{Related empirical evidence for EMEs}

There is a long-running debate on the effectiveness of currency interventions, not just for developed economies, but also for EMEs. Evidence coming from crosscountry studies have found support for an impact of currency interventions on exchange rates. For instance, across a sample of 33 advanced economies and EMEs, Fratzscher et al. (2019) found evidence for the effectiveness of currency interventions in reducing exchange rate volatility but found less convincing evidence as to its impact on the level of the exchange rate. Across a panel of 18 EMEs, Daude et al. (2016) found, on average, currency intervention to be effective in moving the real exchange rate in the desired direction, controlling for deviations from the equilibrium and short-term changes in fundamentals and global financial variables. 
By far, however, findings from individual country studies provide the bulk of the evidence on the effectiveness of currency interventions. Existing evidence for EMEs, mostly from Latin American countries, is mixed overall. For instance, Kohlscheen and Andrade (2014) analyzed the effect of currency swap auctions by the Central Bank of Brazil on the USD/BRL rate, and found that such official currency swap auctions impacted the exchange rate in a significant way. Tapia and Tokman (2004) found that in the case of Chile, currency interventions through the direct spot market and US Dollar denominated papers did not have significant effects. In the case of Colombia, Echavarria et al. (2017) compared the effects of pre-announced day-to-day intervention with respect to discretionary intervention and found that the former had a larger effect than the latter. Also for Colombia, Kuersteiner et al. (2018) exploiting a discontinuous policy rule used by the Central Bank of Colombia found that interventions had significant effects on the exchange rate, although shortlived. Humala and Rodriguez (2010), using Markov regime switching techniques, found that interventions are larger in periods of high exchange rate volatility in the case of Peru. Catalán-Herrera (2016), using official currency intervention data from the Central Bank of Guatemala, found that interventions had a dampening effect on exchange rate volatility but did not have an effect on the level of the exchange rate. Finally, Broto (2013) conducted individual country estimations on currency interventions for Chile, Colombia, Mexico and Peru and found that while it is difficult to establish regularities across the four countries, one clear pattern emerges from the results of this study: isolated interventions help to curb currency volatility, whereas sizable interventions do not have a great influence on the exchange rate.

Outside of Latin American economies, the evidence is relatively fewer and also mixed overall. Using published data from the Central Bank of Turkey, Akinci et al. (2006) found asymmetry in the results in which currency purchases seem to be successful, especially after stabilization of financial markets. Also using published data from the Central Bank of Turkey, Onder and Villamizar-Villegas (2018) found that unannounced currency purchases had a significant effect in reducing exchange rate volatility but appeared to have no effect on exchange rate changes. Announced interventions, on the other hand, did have a significant effect on exchange rate changes and volatility. Using official currency intervention data from the Central Bank of the Czech Republic, Disyatat and Galati (2007) found that interventions did not have an effect on exchange rate volatility, and also had a weak and limited influence on the spot exchange rate. Also using official currency intervention data from the Central Bank of the Czech Republic, Gersl and Holub (2006) find less favorable results compared to Disyatat and Galati (2007), where they found that interventions did not have any impact on the spot exchange rate, while there was a slight increase in its volatility. Finally, Fry-McKibbin and Wanaguru (2013), using 
official currency intervention data from the Central Bank of Sri Lanka found that currency interventions were effective, although in different ways. Specifically, during what they referred to as the low volatility, pre-GFC period currency purchases were effective relative to currency sales. In contrast, during the high global volatility period, currency sales were more important.

\section{Institutional details and data}

\subsection{Institutional framework}

In 1993, Mongolia abandoned the pegged exchange rate against the Soviet rouble, which had been in operation since the communist era. It became evident that the regime was untenable amid the transition to a market economy, trade liberalization and increased activity in the foreign exchange market. After a series of devaluations of the Mongolian tugrik vis-à-vis the US dollar, the legal framework to adopt a flexible exchange rate regime was set up in 1996.

Today, Mongolia is a developing economy, driven largely by its mining sector and economic activity in China. Due to its natural resource based economic structure, the Mongolian tugrik can be viewed as a commodity currency. Over the recent years, exchange rate expectations have been rather one-way as the Mongolian tugrik continues to depreciate against the US dollar, partly due to persistent current account deficits and increased foreign-currency denominated public debt.

In line with its mandate for setting exchange rate policy, the Bank of Mongolia (BOM from hereon) undertakes regular foreign exchange operations to address disorderly market conditions. Intervention activities are directed towards dampening exchange rate volatility and strengthening foreign exchange reserves. The BOM intervenes in the foreign exchange market mainly via its auction mechanism with the objective of promoting transparency and efficiency of the foreign exchange market, while also ensuring stability and market determination of the exchange rate.

\subsection{Foreign exchange auction mechanism and the interbank market}

\subsubsection{Foreign exchange auctions}

The BOM introduced an auction mechanism on the 24 March 2009 to facilitate the development of the domestic foreign exchange market. This allows the central bank to operate directly in the interbank market and manage liquidity needs. The 
FX-auctions have since served as the main platform to determine FX market conditions. Foreign exchange is mainly traded at spot prices, with only a few forward transactions taking place among banks for reserve management purposes. Depending on market conditions, the BOM conducts single-price and multiple-price auctions which are not announced beforehand.

The auctions are held regularly on Tuesdays and Thursdays, inviting bids from commercial banks only. Non-banking financial institutions, businesses and private individuals may engage in trading indirectly through these banks. The auctions take place between 09:30-10:00 am, where banks submit foreign exchange orders indicating the direction, amount and the exchange rate. Banks may place up to three bids, each bid ranging from 1 to 8 million USD. The auction committee ${ }^{6}$ meets at 10:30 am to decide on the amount and exchange rate to be offered. In fulfilling these orders, the auction committee does not allow deviation of more than 2 percent from the BOM reference rate. Unfulfilled orders or rejection of bids are not explained.

\subsubsection{The interbank market}

In contrast to mature interbank markets in developed economies, interbank trading accounts for a relatively small fraction in the Mongolian foreign exchange market. Prior to the establishment of a screen-based system for interbank foreign exchange transactions by the BOM in 2017, commercial banks mostly traded with each other via telephone. Currently, trading activity is mainly conducted through the screen-based system with $\mathrm{T}+1$ settlement. Due to liquidity needs, interbank trading with same-day settlement can be undertaken over the telephone from time to time. Trading between commercial banks tends to dry up if the MNT is expected to depreciate further, a common case scenario in the Mongolian foreign exchange market.

\subsection{Data}

The period of study is from 2 January 2008 to 31 December 2018 during which the BOM conducted official daily amounts of interventions of both purchases and sales of USD, mainly effected through FX auctions. ${ }^{7}$ From October 2017 onward, the

\footnotetext{
6 The auction committee members are: First Deputy Governor, Director of Reserve Management Financial Markets Department, Director of Monetary Policy Department and Chief Economist.

7 We note that the period from 2 January 2008 to 23 March 2009 corresponds to the preauction period during which the BOM conducted direct dealing with banks to carry out its intervention transactions.
} 
data also include interventions conducted in the interbank market. For reasons that will become clearer in the following discussions, we opt to conduct our empirical analysis for three sub-periods: (i) 2 January 2008 to 31 December 2011, (ii) 2 January 2012 to 31 December 2015, and (iii) 2 January 2016 to 31 December 2018. Figure 1 (panels A to C) depicts all currency sales and purchases of US dollars conducted by the central bank for the three respective sub-periods. There are a couple of features in the plot that are worth highlighting. First, in all three panels, currency interventions in Mongolia involved more currency sales than currency purchases, which reflect the depreciating trends of the MNT vis-à-vis the USD for the entire period of the analysis (Figure 2). Second, also across the three panels, interventions tend to be in clusters, some more noticeable than others, and, definitely, there are times during which the central bank intervened more frequently. Third, larger amounts of currency purchases and sales can be observed for the second sub-period (panel B) and third sub-period (panel C) compared to the first sub-period (panel A). Table 1 below provides a more detailed discussion of the currency intervention data.

\section{INSERT FIGURE 1 (PANELS A-C) HERE INSERT FIGURE 2 HERE}

Columns one to three of Table 1 provide a description of the official daily amounts of intervention by the BOM across the three sub-periods. During the first sub-period, out of a total of 1019 trading days, currency interventions were conducted on a total of 282 days, which implies that there were 737 days on which the BOM did not intervene. On intervention days, currency purchases and sales worth less than or equal to USD 30 million were conducted for 61 and 209 days, respectively, of which the minimum intervention amount was USD 0.5 million for purchases, and USD 0.1 million for sales. On the other hand, currency purchases and sales amounting to more than USD 30 million were conducted for only 8 and 4 days, respectively, in which the maximum amount was USD 50 million on either side. In other words, one can then describe the intervention tactic during this sub-period as being conducted with small and frequent amounts on either side.

In contrast, the second sub-period can be characterized by a relatively different intervention tactic pursued by the central bank compared to the first sub-period. During this sub-period, out of a total of 1008 trading days, currency interventions were conducted on a total of 300 days, which suggests that the BOM did not intervene on 708 days. On intervention days, currency purchases and sales worth less than or equal to USD 30 million were conducted on 20 and 202 days, respectively, of which the minimum intervention amount was USD 2.5 million for purchases, and USD 0.6 million for sales. On the other hand, currency purchases were conducted on 
only 4 days of which the maximum daily amount was USD 69 million, whereas currency sales amounting to more than USD 30 million were conducted for 74 days of which the maximum daily amount was USD 95 million. In other words, this subperiod, compared to the first sub-period, can be characterized by an intervention tactic whereby there are infrequent yet large currency purchases on one hand, but with frequent, large amounts of currency interventions in terms of currency sales, on the other.

The intervention tactic of the third sub-period is quite similar to the secondsub-period. Out of a total of 742 trading days, currency interventions were conducted on a total of 172 days, implying that BOM did not intervene on 567 days. On intervention days, similar to the second sub-period, currency sales were conducted frequently and in large amounts, while currency purchases were conducted less frequently (relative to currency sales), but also in large amounts. There is, however, a slight differing nuance between the two sub-periods. In terms of currency purchases, the maximum daily amount of USD 74 million for the third sub-period is relatively larger than that of the second sub-period (USD 69 million), while, in terms of currency sales, the maximum daily amount of USD 89 million for the third subperiod is relatively smaller than the second sub-period. In other words, while in both periods the central bank engaged in frequent currency sales, its preference nonetheless, is to conduct larger currency sales during the second sub-period compared to the third.

\section{Estimation strategy}

When investigating the effectiveness of official currency interventions on the movement of the exchange rate, the main challenge is to address the issue of endogeneity. The endogeneity of interventions to exchange rate movements can produce inconsistent estimates which lead to incorrect causal inferences. The sources of endogeneity that need to be addressed in order to isolate the causal effect of intervention on the changes in the MNT/USD exchange rate are simultaneity and self-selection bias.

Simultaneity, or reverse causality, relates to the two-way causation between currency intervention and the changes in the MNT/USD. Intervention operations may influence the exchange rate, but movements in the exchange rate may also affect the authorities' decision to intervene. To overcome this simultaneity problem, we use a two-stage instrumental variable estimation approach. In the first stage, an ordered probit model is used to estimate the intervention reaction function, from which 
inverse probability weights are constructed. ${ }^{8}$ Then, in the second stage, these weights are combined with a local linear projection type estimator to estimate the outcome equation. We also note that another advantage from the use of an order probit model is that it allows for negative values of the currency intervention instrument, i.e., purchases of USD against sales of MNT. ${ }^{9}$

The two-stage estimation approach also allows us to address the second source of endogeneity, i.e., self-selection bias, where central bank official interventions do not occur randomly, but instead are "self-selected" by the authorities on when to intervene. Considering intervention as a "treatment" and the estimation of the intervention reaction function in the first-stage through an ordered probit model, we can then estimate the "average treatment effect" (ATE) of currency intervention using multinomial propensity scores. This is possible because the inverse probability weights obtained in the first stage are used to adjust our intervention or so-called "treatment variable" to a randomly selected setting, or to mimic a situation of "as if" the decision to intervene by the authorities in Mongolia had been taken at random. We provide further details of these in the discussions below.

\subsection{Intervention reaction function}

In the first stage, we use the ordered probit model to estimate an intervention reaction function across the three sub-periods: (i) 2 January 2008 to 31 December 2011, (ii) 2 January 2012 to 31 December 2015, and (iii) 2 January 2016 to 31 December 2018. We estimate a typical intervention reaction function modelled as follows:

$$
\begin{aligned}
I N T_{t}=\alpha_{0} & +\beta_{0} E X R_{t-1}+\beta_{1} E X R_{t-2}+\beta_{2} E X R_{t-3}+\beta_{3} I N T_{t-1}+\beta_{4} I N T_{t-2} \\
& +\beta_{5} I N T_{t-3}+\beta_{6} M A 21 E X R_{t-1}+\varepsilon_{t}
\end{aligned}
$$

where INT are the ordered intervals or categories of the intervention amount, EXR is the first difference of the logarithm of the MNT/USD exchange rate, MA21EXR is the 21-day moving average of EXR, and $\varepsilon$ is the error term. The ordered categories for the dependent variable, INT, are constructed in each of the sub-periods as follows: for the first sub-period, currency purchases which account for 7 percent of the total

\footnotetext{
${ }^{8}$ We are not the first to use an order probit model in the context of the effectiveness of currency interventions. Using Japanese currency intervention, Ito and Yabu (2007) used it as well to estimate a Japanese intervention reaction function.

${ }^{9}$ The BOM records purchases of USD with a negative sign, while sales of USD are recorded with a positive sign.
} 
intervention days (this share is obtained from Table 1) for this sub-period takes a value of -1 , while currency sales which account for 21 percent (this share is also obtained from Table 1) takes a value of +1 . Given the distribution of the intervention data for this sub-period, we consider that this is the natural choice of the categories to avoid having categories that either have no observations or with very few observations. In other words, this recognizes that, in practice, the data will impose a limit on the fineness of the categories of the intervention amounts. ${ }^{10}$

For the second and third sub-periods, currency purchases again take a value of -1 in view of it accounting for 2.3 percent and 5 percent of the total intervention days (also refer to Table 1) for the second and third sub-periods, respectively. On the other hand, we grouped currency sales into one additional category for these two sub-periods. Specifically, currency sales of less than or equal to USD 30 million take a value of +1 , while currency sales greater than USD 30 million take a value of +2 . Given that currency sales of less than or equal to USD 30 million account for 20 percent and 14 percent for the two sub-periods, respectively, while currency sales of more than USD 30 million account for 7.3 percent for the second sub-period, and 5 percent for the third sub-period (also refer to Table 1), we also believe that these are the natural choices of the categories for grouping the intervention data on currency sales for these two sub-periods. Finally, in all of the sub-periods, days of no intervention take a value of 0 , which then serves as our control or benchmark policy.

4.2. Multinomial treatment (propensity score estimation) and the causal effect of currency intervention

The predicted values from the above ordered probit estimation of the intervention reaction function are used to derive propensity scores, as well as constructing an instrumental variable for the contemporaneous intervention in the second stage outcome equation. Typical of the explanatory variables included in an intervention reaction function, Equation (1) describes the probability of intervention conditional on past interventions and lagged outcomes. The resulting set of conditional distributions defines a function called the policy propensity score.

Following the notation of AJK, formally, the policy propensity score can be expressed as $P\left(D_{t}=d_{j} \mid z_{t}\right)=p^{j}\left(z_{t}, \psi\right)$. This is a flexible parametric model with parameter determined by the policy regime $(\psi)$. $D_{t}$ is simply the ordered intervals or categories of the intervention amount, which as discussed above, takes discrete values $d_{0}, \ldots, d_{j}$. In addition, $z_{t}$ are the predetermined variables found on the right-

${ }^{10}$ The seminal article of Hausman et al. (1992), which introduced ordered probit models into the finance literature, also made this reasonable point. 
hand side of Equation (1), such as the lagged changes in the MNT/USD exchange rate and lagged $D_{t}$.

As discussed by AJK, their method leans on parametric models for the intervention reaction function but requires no functional form assumptions for the outcome equation. Their approach does not define or estimate structural innovations for the policy process, nor develop, solve, or simulate a model. To then estimate, $\theta_{j}$, the average treatment effect of currency intervention on the changes in the exchange rate, the first few steps of AJK are as follows:

- Fit the model $p^{j}\left(z_{t}, \psi\right)=\operatorname{Pr}\left(D_{t}=d_{j} \mid z_{t}, \psi\right)$.

- Estimate the predicted probabilities $\hat{p}_{t}^{j}=p^{j}\left(z_{t}, \hat{\psi}\right)$ for all $j, t$.

- Drop observations with very low $p^{j}\left(z_{t}, \hat{\psi}\right)$ when $1\left\{D_{t}=d_{j}\right\}=1$. This removes a few observations that receive extreme weights. ${ }^{11}$

- Construct the inverse propensity weights, expressed as follows:

$$
\delta_{t, j}(\psi)=\frac{1\left\{D_{t}=d_{j}\right\}}{p^{j}\left(z_{t}, \psi\right)}-\frac{1\left\{D_{t}=d_{0}\right\}}{p^{0}\left(z_{t}, \psi\right)}
$$

From this point on, we deviate slightly from AJK by incorporating the step in terms of purging our outcome variable, $y_{t}$, the changes in the MNT/USD, of any influence from the other instruments of monetary policy like the target policy rate. ${ }^{12}$ To do this, we include in the vector $z_{t}$ contemporaneous and lagged terms of the target policy rate, and this new vector we denote as $w_{t}$. After this, we regress $y_{t}$ on $w_{t}$ and a constant and construct the residuals $\ddot{y}_{t, j}$. Finally, the vector of estimated responses to policy choice $j$ relative to the control or benchmark policy are computed as:

$$
\hat{\theta}_{j, L}=\frac{\sum_{t=1}^{T} \ddot{y}_{t, L} \delta_{t, j}}{T}
$$

where subscript $L$ corresponds to the trading horizon. Recall that the policy choices across the three sub-periods are as follows: currency purchases $(-1)$ and sales $(+1)$ for the first sub-period; currency purchases $(-1)$, currency sales of less than or

\footnotetext{
${ }^{11}$ AJK drop observations that have $p^{j}<0.025$, while in our case we drop observations that have $p^{j}<0.085$ to remove a few observations that receive extreme weights.

12 The original codes to implement AJK (2016) are available on Prof. Guido Kuersteiner's website at: http://econweb.umd.edu/ kuersteiner/research UMD.html. Portions of the codes were modified to implement the additional steps we carry out in this paper. We gratefully acknowledge him for making the original codes available.
} 
equal to USD 30 million $(+1)$, and currency sales of more than USD 30 million $(+2)$ for the other two sub-periods. Again, recall that in all three sub-periods, the benchmark policy is of no intervention.

\section{Empirical results}

\subsection{Main results}

We begin by first reporting our propensity score estimates of the intervention reaction function in Equation (1). In conducting our estimation of the propensity scores using ordered probit, we first include all explanatory variables. The insignificant explanatory variables are then excluded, and a restricted version of the reaction function is re-estimated across all three sub-periods. Tables 2 to 4 display the results. Table 2 presents the ordered probit estimates of the marginal effects of the significant explanatory variables in the reaction function for the period January 2008 to November 2011, Table 3 the marginal effects for the period January 2012 to November 2015, and Table 4 for the period January 2016 to November 2018. Since responses of the changes in the MNT/USD are shifted up to 20 days forward, the end dates for the outcome variable in each of the respective tables are end-December 2011, end-December 2015 and end-December 2018, respectively.

\section{INSERT TABLE 2 HERE \\ INSERT TABLE 3 HERE \\ INSERT TABLE 4 HERE}

Table 2 indicates that both purchases (column 1) and sales of USD (column 2) react to the previous day's changes in the MNT/USD exchange rate as well as to the 21-day moving average of the changes in the MNT/USD exchange rate. In addition, both purchases and sales of USD conducted on a given day are affected by similar types of transactions in interventions, which were carried out on the previous day as well as two and three days before that. Tables 3 and 4 show that purchases of USD (column 1), sales of USD less than or equal to 30 million (column 2), and sales of USD of more than 30 million (column 3) all react similarly to one and two-day lagged changes in MNT/USD (Table 4 shows that for the period January 2016 to November 2018, all three types of transactions in interventions further react to three-day lagged changes in the exchange rate). Likewise, intervention conducted on a given day reacts to intervention carried out on the previous day, intervention effected two-days before, and to intervention made three days before. Moreover, it is interesting to note that the partition boundary estimates of the ordered probit are estimated with high 
precision for all three sub-periods, suggesting that our choice of the cut-offs of the categories in our intervention data are appropriate. Overall, the ordered probit estimates of the reaction function suggest not only that intervention reacts to past trends in the changes in MNT/USD exchange rate, but the conduct of intervention by the central bank is typically clustered, which duly confirms our earlier visual examination of the intervention data.

We now turn to the dynamic causal effects of currency intervention on changes in the MNT/USD exchange rate. All responses are measured as cumulative percent changes over a horizon of 20 trading days. Figures 3 to 5 present the main results of our estimated responses, which are constructed using the propensity scores estimates presented above (Figure 3 corresponds to propensity scores estimates reported in Table 2, Figure 4 corresponds to propensity score estimates presented in Table 3, and Figure 5 corresponds to score estimates shown in Table 4 ). The figures also show the 68 percent confidence bands. Figure 3 indicates that there is a delayed response of the changes in the exchange rate from purchases of USD (left-panel), which only begins to depreciate after 5 trading days, and reaches its peak response of about a 0.25 percent increase in the MNT/USD exchange rate (i.e., depreciation of the MNT) closer to the end of the impulse horizon. These responses, however, are statistically insignificant. In contrast, the response from changes in the exchange rate from sales of USD (right-panel) is almost immediate, and for nearly the entirety of the impulse horizon, indicating a consistent decrease in the exchange rate (i.e., appreciation of the MNT). While the responses are imprecisely estimated for almost all horizons, it appears that sales of USD for the first sub-period have a short-lived and significant causal effect of close to 0.2 percent on the changes in the exchange rate around the beginning of the second week of the impulse horizon.

\section{INSERT FIGURE 3 HERE}

Figure 4 shows the responses of changes in the exchange rate from purchases of USD (left-panel), sales of USD less than or equal to 30 million (middle-panel), and sales of USD of more than 30 million (right-panel) for the second sub-period. The responses from purchases of USD, while imprecisely estimated, indicate that for some horizons, currency intervention had the opposite effect of an appreciation in the MNT. Sales of USD less than or equal to 30 million had a statistically significant effect for almost the first three weeks, however, sales of USD of these amounts of currency interventions have an opposite or perverse effect on changes in the exchange rate in terms of an appreciation in the MNT. Finally, the effects of sales of USD of more than 30 million are statistically different from zero for the first week, and these 
effects are of the correct sign (appreciation of the MNT vis-à-vis the USD) with the maximal effect at 0.1 percent.

\section{INSERT FIGURE 4 HERE}

Figure 5 presents the responses of the changes in the exchange rate from purchases of USD (left-panel), sales of USD less than or equal to 30 million (middlepanel), and sales of USD of more than 30 million (right-panel) this time for the third sub-period. The effects of purchases of USD are of the correct sign for almost the entire horizon but are imprecisely estimated with wide confidence bands. Sales of USD less than or equal to 30 million had a statistically significant effect during the entire second week of the impulse horizon. However, such sales of USD of these amounts also have the perverse effect of an appreciation in the MNT. Finally, the responses from sales of USD of more than 30 million are statistically different from zero for almost the first week, and such currency interventions move the MNT in the correct direction in terms of a currency appreciation vis-à-vis the USD by about 0.1 percent.

\section{INSERT FIGURE 5 HERE}

\subsection{Robustness tests}

This section examines the robustness of our main results along various dimensions: first, in addition to the inclusion of contemporaneous and lagged terms of the target policy rate in the vector $w_{t}$, we further control for the effects of other instruments of monetary policy in Mongolia by, (i) including contemporaneous and lagged terms of the domestic reserve requirement, (ii) include contemporaneous and lagged terms of the foreign-exchange reserve requirement, and, (iii) both include contemporaneous and lagged terms of the domestic reserve requirement and foreignexchange reserve requirement in vector $w_{t}$. Second, we also check for the sensitivity of our main results by including contemporaneous and lagged terms of daily gold prices (in logs) in vector $w_{t}$. In terms of the impulse responses, we again present the responses of the changes in the exchange rate to currency intervention over a horizon of 20 trading days for the three sub-periods.

5.2.1. Include contemporaneous and lagged terms of the domestic reserve requirement 
In addition to the policy rate, including contemporaneous and lagged terms of the domestic reserve requirement produce impulse responses depicted in Figures 6-8 that are very similar to our main results, except that now purchases of USD for the first sub-period (Figure 6, left-panel) reach a higher peak response compared to the same panel in Figure 3. In addition, purchases of USD for the third sub-period (Figure 8, left-panel) elicit a slightly bigger response compared to the same panel in Figure 5. Similar to the main results, however, these observed differences in responses in the changes in exchange rates are again imprecisely estimated. More importantly though, our main findings hold: a short-lived and significant causal effect of sales of USD on the changes in the exchange rate around the beginning of the second week of the impulse horizon for the first sub-period (Figure 6, right-panel), a statistically significant and correctly signed effect of sales of USD of more than 30 million for the first week of the horizon during the second sub-period (Figure 7, right-panel) as well as for about the first week during the third sub-period (Figure 8, right-panel), although the latter indicate slightly wider confidence bands.

\title{
INSERT FIGURE 6 HERE \\ INSERT FIGURE 7 HERE \\ INSERT FIGURE 8 HERE
}

\subsubsection{Include contemporaneous and lagged terms of the foreign-exchange reserve requirement}

Our next sensitivity test is to this time include contemporaneous and lagged terms of the foreign-exchange reserve requirement in addition to contemporaneous and lagged terms of the policy rate. Figures 9-11 present the impulse responses. There is practically no change in the impulse responses, except that purchases of USD for the first sub-period (Figure 9, left-panel) again reach a higher peak response compared to the same panel in Figure 3. These responses are statistically insignificant, however. Moreover, the effects of sales of USD less than or equal to 30 million (Figure 10, middle panel) in the second sub-period are slightly sharper in statistical significance at most horizons compared to the same panel in Figure 4, although the responses again indicate an opposite or perverse effect on changes in the exchange rate in terms of an appreciation in the MNT. Despite these very slight differences, our main findings remain intact.

\author{
INSERT FIGURE 9 HERE \\ INSERT FIGURE 10 HERE \\ INSERT FIGURE 11 HERE
}




\subsubsection{Both include contemporaneous and lagged terms of the domestic and foreign-exchange reserve requirements}

Our final sensitivity test in terms of controlling for the effects of other policies in addition to the policy rate is to include both contemporaneous and lagged terms of the domestic and foreign-exchange reserve requirements. Figures 12-14 present the impulse responses. As depicted in these figures, the impulse responses are almost identical to the responses presented in our second sensitivity test above. In view of this, these results again do not alter our main findings.

\section{INSERT FIGURE 12 HERE \\ INSERT FIGURE 13 HERE \\ INSERT FIGURE 14 HERE}

\subsubsection{Include contemporaneous and lagged terms of gold prices}

Recognizing that Mongolia is a major commodity exporter, we also include in vector $w_{t}$, in addition to the policy rate, contemporaneous and lagged terms of daily gold prices (in logs), one of Mongolia's major exports. ${ }^{13}$ The impulse responses are depicted in Figures 15 to 17. The impulse responses are once again similar to the responses in the main results, except that now the effects of sales of USD on the changes in the exchange rate for the first sub-period (Figure 15, right-panel) are not only statistically significant around the beginning of the second week, but also during the third week of the impulse horizon, which further reinforces our main findings. In Figure 16, the effects of purchases of USD (left-panel) in the second sub-period, although statistically insignificant, are correctly signed (i.e., depreciation of the MNT) for most of the impulse horizons compared to the same panel in Figure 4. Also, in the same figure, sales of USD less than or equal to 30 million (middle panel) are also slightly sharper in statistical significance compared to the same panel in Figure 4, but then again the responses to currency intervention suggest a perverse effect in terms of an appreciation in the MNT. In Figure 17, purchases of USD for the third sub-period (left-panel) also elicit a slightly bigger response compared to the same panel in Figure 5, while the interpretations that we accorded to the middle panel of Figure 16 can also be made to the middle panel of Figure 17 for sales of

\footnotetext{
${ }^{13} \mathrm{We}$ also tried to include in vector $w_{t}$, contemporaneous and lagged terms of daily copper prices, another of Mongolia's major exports. In doing so, however, these led to a substantial loss of information in our data sample due to the less-frequent data availability of daily copper prices compared to gold prices.
} 
USD less than or equal to 30 million. Despite these observed differences in Figures 16 to 17 relative to our main results, our main findings still stand..$^{14,15}$

\section{INSERT FIGURE 15 HERE \\ INSERT FIGURE 16 HERE \\ INSERT FIGURE 17 HERE}

\section{Conclusion}

Although EME central banks actively intervene in currency markets, there is a long-running and far from settled debate as to its effectiveness in affecting exchange rates. In this study, we use unique daily data on currency interventions by the BOM to analyze the impact of these interventions on changes in the MNT/USD exchange rate. The period we examined spans the time in which the country, as a major commodity exporter, experienced the dramatic rise and fall in international commodity prices with significant consequences on its exchange rate.

Our results show that currency interventions are effective in Mongolia, although they differ in certain ways. Currency sales are effective in moving changes in the MNT/USD in the right direction, most especially when carried out in larger amounts and when implemented frequently. Our results also indicate that this shortrun effectiveness can last from one to three weeks, although we find the magnitude of the daily effect to be relatively small. We do not find support, however, that currency purchases are effective, although this can be due to the nature of the sample period that we examine which is largely dominated by currency sales.

It is then interesting to compare our results with some of the existing literature on the effectiveness of currency intervention, subject to the caveat that existing

\footnotetext{
${ }^{14}$ We also conducted an extension of this sub-section's robustness test for the three subperiods by including (i) contemporaneous and lagged terms of the domestic reserve requirement, (ii) contemporaneous and lagged terms of the foreign-exchange reserve requirement, and, (iii) both include contemporaneous and lagged terms of the domestic reserve requirement and foreign-exchange reserve requirement in vector $w_{t}$, in addition to the contemporaneous and lagged terms of the policy rate and gold prices. We obtain impulse responses that are very similar to the ones reported in the main text. These results are available upon request.

${ }^{15}$ We also further conducted a sensitivity test in which we included in the intervention reaction function a measure of conditional volatility obtained via a $\operatorname{GARCH}(1,1)$ model. But these estimates of the conditional volatility came out as insignificant in all of the ordered probit estimations for the three sub-periods. These results are also available upon request.
} 
studies employed distinct methods and different sample periods. Our finding that only large amounts of intervention matter is similar to those of Fatum and Yamamoto (2014), although we note that Fatum and Yamamoto (2014) derived their finding using advanced economy currency interventions, i.e., Japanese intervention data. In terms of the frequency of the intervention, our results are also similar to Echevarria et al. (2017) and Dominguez et al. (2013). The former found that preannounced and constant daily interventions by the Central Bank of Colombia were more important than discretionary or infrequent interventions, while the latter study found that only daily or frequent reserves sales by the Czech National Bank have a statistically significant appreciation of the Czech Koruna. Based on the explanation by Dominguez et al. (2013), it may well be that frequent currency interventions can be interpreted by the market as a permanent policy, with such intervention operations to endure. Finally, in terms of the duration and size of the effect, our findings are quite comparable to the results of Kuersteiner et al. (2018) for the case of Colombia. This study found that central bank purchases of dollars led to an approximately 0.8 percent depreciation of the Colombian peso on the day of the intervention, and this effect persisted for 2-3 weeks. 


\section{References}

Akinci, Ö., Çulha, O.Y., Özlale, Ü., Şahinbeyouğlu, G., 2006. The effectiveness of foreign exchange interventions under a floating exchange rate regime for the Turkish economy: a post-crisis period analysis. Applied Economics 38, 13711388 .

Angrist, J., Jorda, O., Kuersteiner, G., 2018. Semiparametric estimates of monetary policy effects: string theory revisited. Journal of Business and Economic Statistics 36 (1), 371-387.

Bailie, R.T., Osterberg, W.P., 1997. Why do central banks intervene? Journal of International Money and Finance 16, 909-919.

Bank for International Settlements, 2019. Reserve Management and FX Intervention. BIS Papers, no 104.

Broto, C., 2013. The effectiveness of forex interventions in four Latin American countries. Emerging Markets Review 17, 224-240.

Catalán-Herrera, J., 2016. Foreign exchange market interventions under inflation targeting: The case of Guatemala. Journal of International Financial Markets, Institutions \& Money 42, 101-114.

Chamon, M., Hofman, D., Lanau, S., Rawat, U., Werner, A., 2019. The effectiveness of intervention in: Chamon, M., Hofman, D., Magud, N., Werner, A. (Eds.), Foreign Exchange Intervention in Inflation Targeters in Latin America. International Monetary Fund, Washington, DC, pp. 43-62.

Daude, C., Levy Yeyati, E., Nagengast, A., 2016. On the effectiveness of exchange rate interventions in emerging markets. Journal of International Money and Finance 64, 239-261.

Disyatat, P., Galati, G., 2007. The effectiveness of foreign exchange intervention in emerging market countries: Evidence from the Czech koruna. Journal of International Money and Finance 26, 383-402. 
Domanski, D., Kohlscheen, E., Moreno, R., 2016. Foreign exchange market intervention in EMEs: what has changed? BIS Quarterly Review, Bank for International Settlements.

Dominguez, K.M., Fatum, R., Vacek, P., 2013. Do sales of foreign exchange reserves lead to currency appreciation? Journal of Money, Credit, and Banking 45 (5), 867-890.

Dominguez, K.M., 1998. Central bank intervention and exchange rate volatility. Journal of International Money and Finance 17, 161-190.

Dominguez, K.M., Frankel, J., 1993. Does foreign exchange intervention matter? The portfolio effect. American Economic Review 83, 1356-1369.

Echavarria, J.J., Melo-Velandia, L.F., Villamizar-Villegas, M., 2017. The impact of pre-announced day-to-day interventions on the Colombian exchange rate. Empirical Economics 55, 1319-1336.

Edison, H., Cashin, P., Liang, H., 2006. Foreign exchange intervention and the Australian dollar: Has it mattered? International Journal of Finance and Economics 11, 155-171.

Edison, H., 1993. The effectiveness of central bank intervention: a survey of the literature after 1982. Special Papers in International Economics, vol. 18, Princeton University.

Fatum, R., Yamamoto, Y., 2014. Large versus small foreign exchange interventions. Journal of Banking and Finance 43, 114-123.

Fatum, R., Hutchison, M., 2010. Evaluating foreign exchange intervention: Selfselection, counterfactuals and average treatment effects. Journal of International Money and Finance 29, 570-584.

Fatum, R., Hutchison, M., 2006. Effectiveness of official daily foreign exchange market intervention operations in Japan. Journal of International Money and Finance 25, 199-219. 
Fatum, R., Hutchison, M., 1999. Is intervention a signal of future monetary policy? Evidence from the Federal Funds Futures Market. Journal of Money, Credit and Banking 31 (1), 54-69.

Fratzscher, M., Gloede, O., Menkhoff, L., Sarno, L., Stöhr, T., 2019. When is foreign exchange intervention effective? Evidence from 33 Countries. American Economic Journal: Macroeconomics 11(1), 132-156.

Fry-McKibbin, R.A., Wanaguru, S., 2013. Currency intervention: A case study of an emerging market. Journal of International Money and Finance 37, 25-47.

Gersl, A., Holub, T., 2006. Foreign exchange interventions under inflation targeting: The Czech experience. Contemporary Economic Policy 24 (4), 475-491.

Glynn, A., Quinn, K.M., 2010. An introduction to the augmented inverse propensity weighted estimator. Political Analysis 18 (1), 36-56.

Hausman, J., Lo, A., MacKinlay, A.C., 1992. An ordered probit analysis of transaction stock prices. Journal of Financial Economics 31, 319-379.

Humala, A., Rodriguez, G., 2010. Foreign exchange intervention and exchange rate volatility in Peru. Applied Economics Letters 17 (15), 1485-1491.

Hutchison, M. 2003. Intervention and exchange rate stabilization policy in developing countries. International Finance 6 (1), 109-127.

Ito, T., Yabu, T., 2007. What prompts Japan to intervene in the Forex market? A new approach to a reaction function. Journal of International Money and Finance 26, 193-212.

Jorda, O., Taylor, A., 2015. The time for austerity: estimating the average treatment effect of fiscal policy. Economic Journal 126, 219-255.

Kohlscheen, E., Andrade, S., 2014. Official FX interventions through derivatives. Journal of International Money and Finance 47, 202-216. 
Kuersteiner, G., Phillips, D.C., Villamizar-Villegas, M., 2018. Effective sterilized foreign exchange intervention? Evidence from a rule-based policy. Journal of International Economics 113, 118-138.

Lunceford, J.K., Davidian, M., 2004. Stratification and weighting via the propensity score in estimation of causal treatment effects: a comparative study. Statistics in Medicine 23 (19), 2937-2960.

Menkhoff, L., 2013. Foreign exchange intervention in emerging markets: A survey of empirical studies. World Economy 36 (9): 1187-1208.

Onder, Y.K., Villamizae-Villegas, M., 2018. The effects of monetary and exchange rate policy shocks: evidence from an emerging market economy. International Journal of Central Banking 14 (1), 159-199.

Ordoñez-Callamand, D., Hernandez-Leal, J.D., Villamizar-Villegas, M., 2018. When multiple objectives meet multiple instruments: identifying simultaneous monetary shocks. International Review of Economics and Finance 58, 78-101.

Pontines, V., 2018. Self-selection and treatment effects: revisiting the effectiveness of foreign exchange intervention. Journal of Macroeconomics 57, 299-316.

Sarno, L., Taylor, M., 2001. Official intervention in the foreign exchange market: is it effective and if so, how does it work? Journal of Economic Literature 34, 839-868.

Tapia, M., Tokman, A., 2004. Effects of foreign exchange intervention under public information: The Chilean Case. Economia 4 (2), 215-256.

Villamizar-Villegas, M., Perez-Reyna, D., 2017. A theoretical approach to sterilized foreign exchange intervention. Journal of Economic Survey 31, 343-365.

Villamizar-Villegas, M., 2016. Identifying the effects of simultaneous monetary policy shocks. Contemporary Economic Policy 34 (2), 268-296. 
Table 1

Official Mongolian daily foreign exchange interventions

\begin{tabular}{|c|c|c|c|}
\hline & $\begin{array}{c}\text { First } \\
\text { sub-period: } \\
\text { January } 2008 \\
\text { to } \\
\text { December } 2011 \\
(1) \\
\end{array}$ & $\begin{array}{c}\text { Second } \\
\text { sub-period: } \\
\text { January } 2012 \\
\text { to } \\
\text { December } 2015 \\
(2) \\
\end{array}$ & $\begin{array}{c}\text { Third } \\
\text { sub-period: } \\
\text { January } 2016 \\
\text { to } \\
\text { December } 2018 \\
(3) \\
\end{array}$ \\
\hline Total intervention days & 282 & 300 & 175 \\
\hline Average daily amount & 0.9 & 20 & 14 \\
\hline $\begin{array}{c}\text { Purchases of USD } \\
\text { (Maximum daily amount) }\end{array}$ & 50 & 69 & 74 \\
\hline $\begin{array}{c}\text { Purchases of USD } \\
\text { (Minimum daily amount) }\end{array}$ & 0.5 & 2.5 & 1.5 \\
\hline $\begin{array}{c}\text { Sales of USD } \\
\text { (Maximum daily amount) }\end{array}$ & 50 & 95 & 89 \\
\hline $\begin{array}{c}\text { Sales of USD } \\
\text { (Minimum daily amount) }\end{array}$ & 0.1 & 0.6 & $8.9 \mathrm{E}-16$ \\
\hline $\begin{array}{l}\text { Purchases of USD of more } \\
\text { than } 30 \text { million (\# days) }\end{array}$ & 8 & 4 & 9 \\
\hline $\begin{array}{c}\text { Purchases of USD less than } \\
\text { or equal to } 30 \text { million } \\
\text { (\# days) }\end{array}$ & 61 & 20 & 25 \\
\hline $\begin{array}{c}0 \text { (No currency } \\
\text { intervention) (\# days) }\end{array}$ & 737 & 708 & 567 \\
\hline $\begin{array}{l}\text { Sales of USD less than } \\
\text { or equal to } 30 \text { million } \\
\text { (\# days) }\end{array}$ & 209 & 202 & 104 \\
\hline $\begin{array}{l}\text { Sales of USD of more than } \\
30 \text { million (\# days) }\end{array}$ & 4 & 74 & 37 \\
\hline
\end{tabular}

Notes: All amounts are in millions of USD. Purchases of USD are recorded with a negative sign (-) (absolute values are reported in the table), while sales of USD are recorded with a positive sign $(+)$. Average daily amount refers to intervention days only.

Source: Raw data obtained from Bank of Mongolia. 
Table 2

Ordered probit estimates of the intervention reaction function

January 2008 to November 2011

\begin{tabular}{|c|c|c|c|c|}
\hline \multirow{2}{*}{ Parameters } & \multicolumn{2}{|c|}{ (1) } & \multicolumn{2}{|c|}{$(2)$} \\
\hline & \multicolumn{2}{|c|}{ Purchases of USD } & \multicolumn{2}{|c|}{ Sales of USD } \\
\hline Intervention, Lag1 & $-0.038^{* * *}$ & $(0.012)$ & $0.057^{* * *}$ & $(0.017)$ \\
\hline Intervention, Lag2 & $-0.107^{* * *}$ & $(0.013)$ & $0.162^{* * *}$ & $(0.015)$ \\
\hline Intervention, Lag3 & $-0.110^{* * *}$ & $(0.013)$ & $0.166^{* * *}$ & $(0.016)$ \\
\hline Changes in Exchange Rate, Lag1 & $-0.040^{* *}$ & $(0.016)$ & $0.060^{* *}$ & $(0.025)$ \\
\hline 21-day moving average of Changes in Exchange Rate & $-0.062^{*}$ & $(0.036)$ & $0.094^{*}$ & $(0.054)$ \\
\hline \multicolumn{5}{|l|}{ Partition boundaries } \\
\hline Cut Point 1 & & $-1.740^{* * *}$ & $(0.075)$ & \\
\hline Cut Point 2 & & $1.570^{* * *}$ & $(0.075)$ & \\
\hline Log Likelihood & \multicolumn{4}{|c|}{-472.00} \\
\hline Observations & \multicolumn{4}{|c|}{998} \\
\hline
\end{tabular}


Table 3

Ordered probit estimates of the intervention reaction function

January 2012 to November 2015

\begin{tabular}{|c|c|c|c|}
\hline & $(1)$ & $(2)$ & $(3)$ \\
\hline & Purchases of USD & Sales of USD less than or equal to 30 million & Sales of USD of more than 30 million \\
\hline \multicolumn{4}{|l|}{ Parameters } \\
\hline Intervention, Lag1 & $0.029 * * * \quad(0.006)$ & $-0.095^{* * *}(0.012)$ & $-0.069^{* * *}(0.010)$ \\
\hline Intervention, Lag2 & $-0.020^{* * *}(0.004)$ & $0.066^{* * *}(0.011)$ & $0.048^{* * *}(0.009)$ \\
\hline Intervention, Lag3 & $-0.029^{* * *}(0.006)$ & $0.095^{* * *}(0.011)$ & $0.069^{* * *}(0.009)$ \\
\hline Changes in Exchange Rate, Lag1 & $-0.043^{* * *}(0.011)$ & $0.143^{* * *}(0.027)$ & $0.104^{* * *}(0.021)$ \\
\hline Changes in Exchange Rate, Lag2 & $-0.021^{* *}(0.009)$ & $0.071^{* * *}(0.027)$ & $0.051^{* * *}(0.020)$ \\
\hline \multicolumn{4}{|l|}{ Partition boundaries } \\
\hline Cut Point 1 & & $-2.121^{* * *}(0.104)$ & \\
\hline Cut Point 2 & & $0.878^{* * *}(0.065)$ & \\
\hline Cut Point 3 & & $1.867^{* * *}(0.082)$ & \\
\hline Log Likelihood & & -742.45 & \\
\hline Observations & & 986 & \\
\hline
\end{tabular}

Notes: (i) Standard errors in parentheses, (ii) ${ }^{*} \mathrm{p}<0.10,{ }^{* *} \mathrm{p}<0.05,{ }^{* * *} \mathrm{p}<0.01$ 
Table 4

Ordered probit estimates of the intervention reaction function

January 2016 to November 2018

\begin{tabular}{|c|c|c|c|}
\hline & $(1)$ & $(2)$ & (3) \\
\hline & Purchases of USD & Sales of USD less than or equal to 30 million & Sales of USD of more than 30 million \\
\hline \multicolumn{4}{|l|}{ Parameters } \\
\hline Intervention, Lag1 & $0.031^{* * *}(0.009)$ & $-0.051^{* * *}(0.014)$ & $-0.030^{* * *}(0.009)$ \\
\hline Intervention, Lag2 & $-0.037^{* * *}(0.009)$ & $0.062^{* * *}(0.012)$ & $0.036^{* * *}(0.009)$ \\
\hline Intervention, Lag3 & $-0.042^{* * *}(0.009)$ & $0.069^{* * *}(0.013)$ & $0.041^{* * *}(0.009)$ \\
\hline Changes in Exchange Rate, Lag1 & $-0.123^{* * *}(0.029)$ & $0.204^{* * *}(0.042)$ & $0.120^{* * *}(0.028)$ \\
\hline Changes in Exchange Rate, Lag2 & $-0.062^{* *} \quad(0.028)$ & $0.104^{* *}(0.045)$ & $0.061^{* *}(0.027)$ \\
\hline Changes in Exchange Rate, Lag3 & $0.045^{*} \quad(0.026)$ & $-0.074^{*}(0.043)$ & $-0.043^{*}(0.026)$ \\
\hline \multicolumn{4}{|l|}{ Partition boundaries } \\
\hline Cut Point 1 & & $-1.718^{* * *}(0.089)$ & \\
\hline Cut Point 2 & & $1.175^{* * *}(0.070)$ & \\
\hline Cut Point 3 & & $2.048^{* * *}(0.097)$ & \\
\hline Log Likelihood & & -493.35 & \\
\hline Observations & & 721 & \\
\hline
\end{tabular}


Figure 1

Panel A. Daily intervention volume (in millions of USD), January 2008 - December 2011

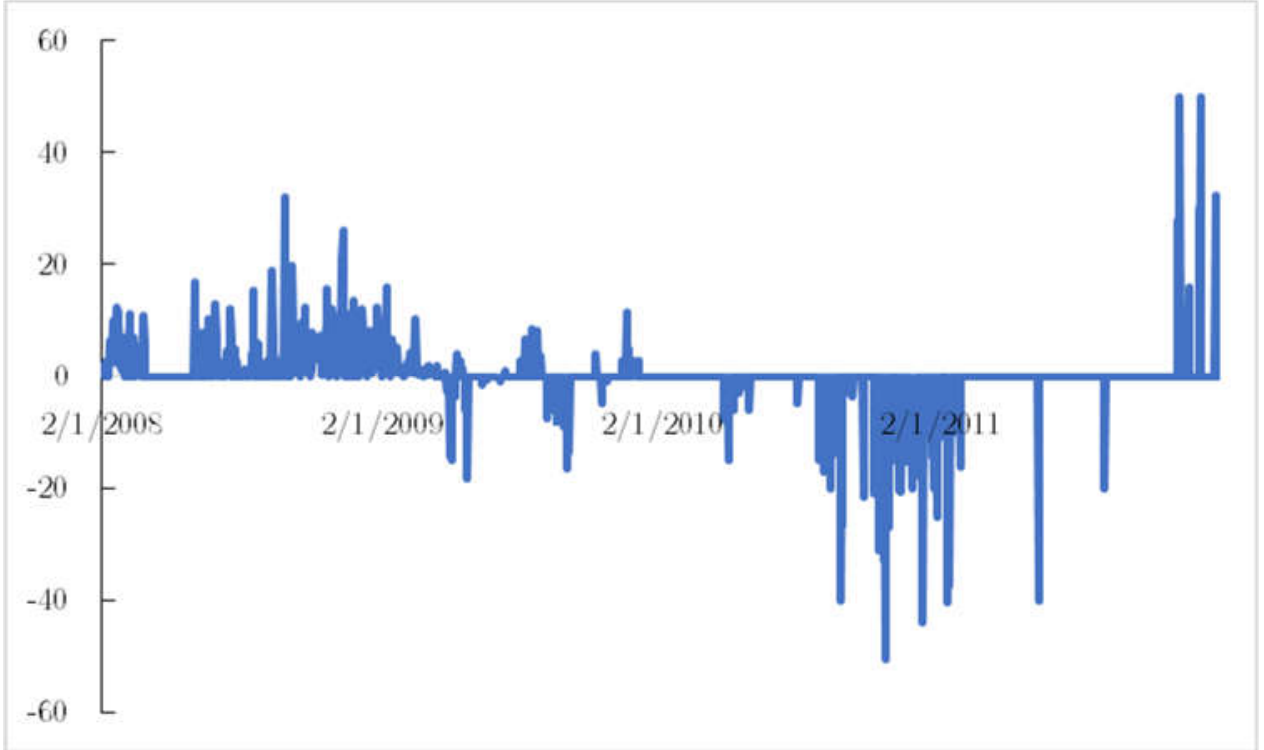

Notes: All amounts are in millions of USD. Negative amounts are purchases of USD, while positive amounts are sales of USD. 
Panel B. Daily intervention volume (in millions of USD), January 2012 - December 2015

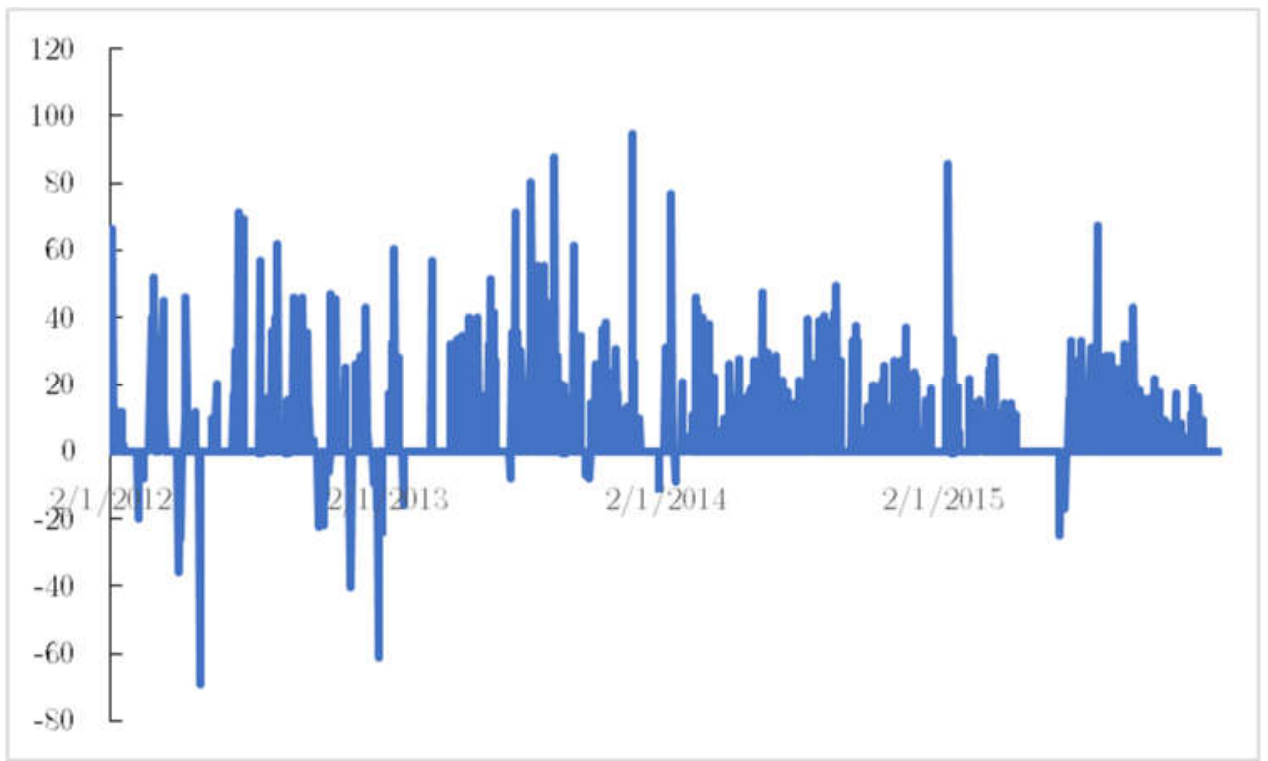

Notes: All amounts are in millions of USD. Negative amounts are purchases of USD, while positive amounts are sales of USD. 
Panel C. Daily intervention volume (in millions of USD), January 2016 - December 2018

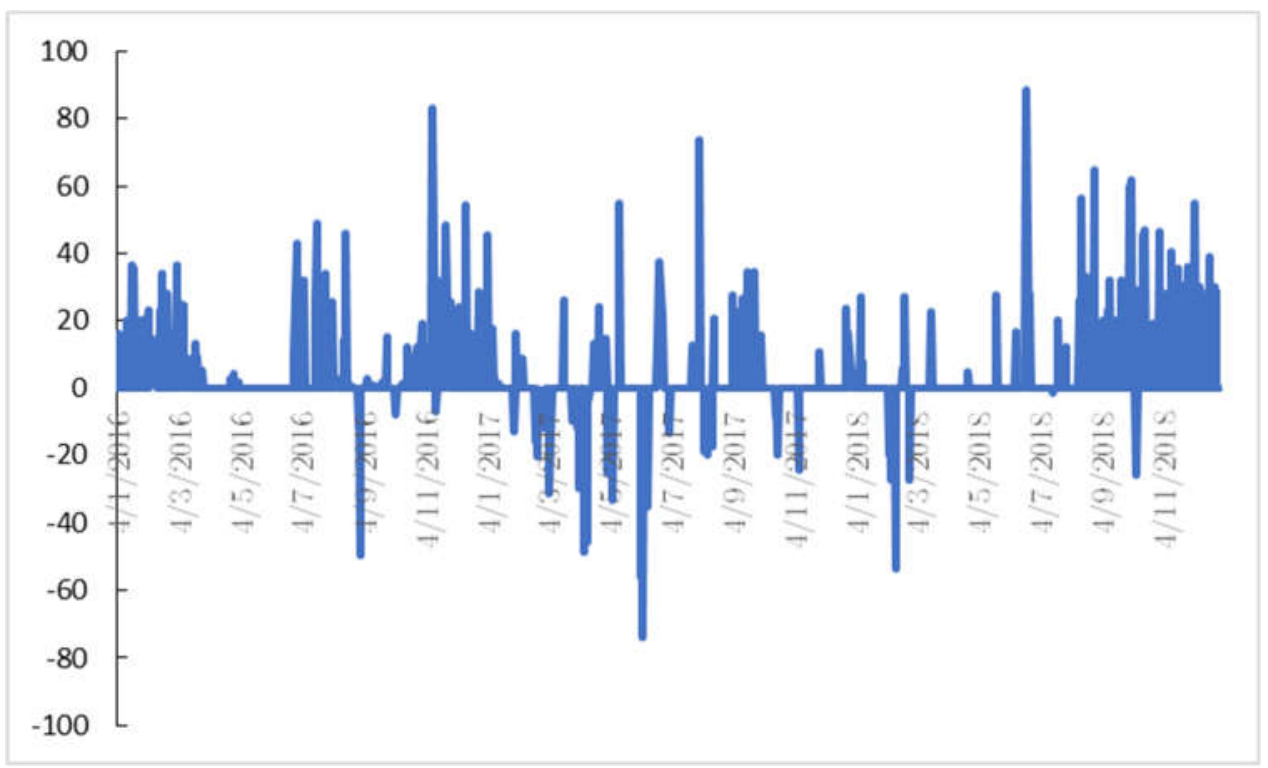

Notes: All amounts are in millions of USD. Negative amounts are purchases of USD, while positive amounts are sales of USD. 
Figure 2

MNT/USD exchange rate, January 2008 - December 2018

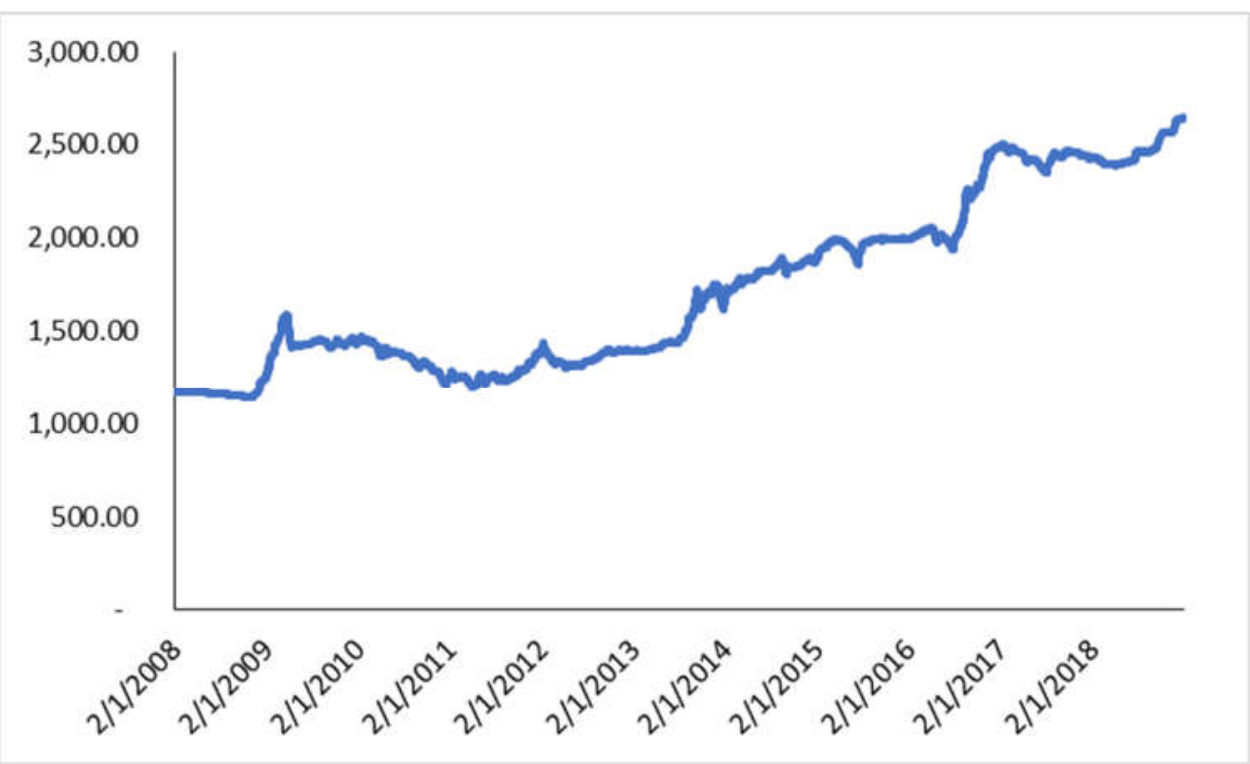




\section{Figure 3}

Estimated effects of intervention on changes in the MNT/USD rate,

January 2008 to December 2011: Main results
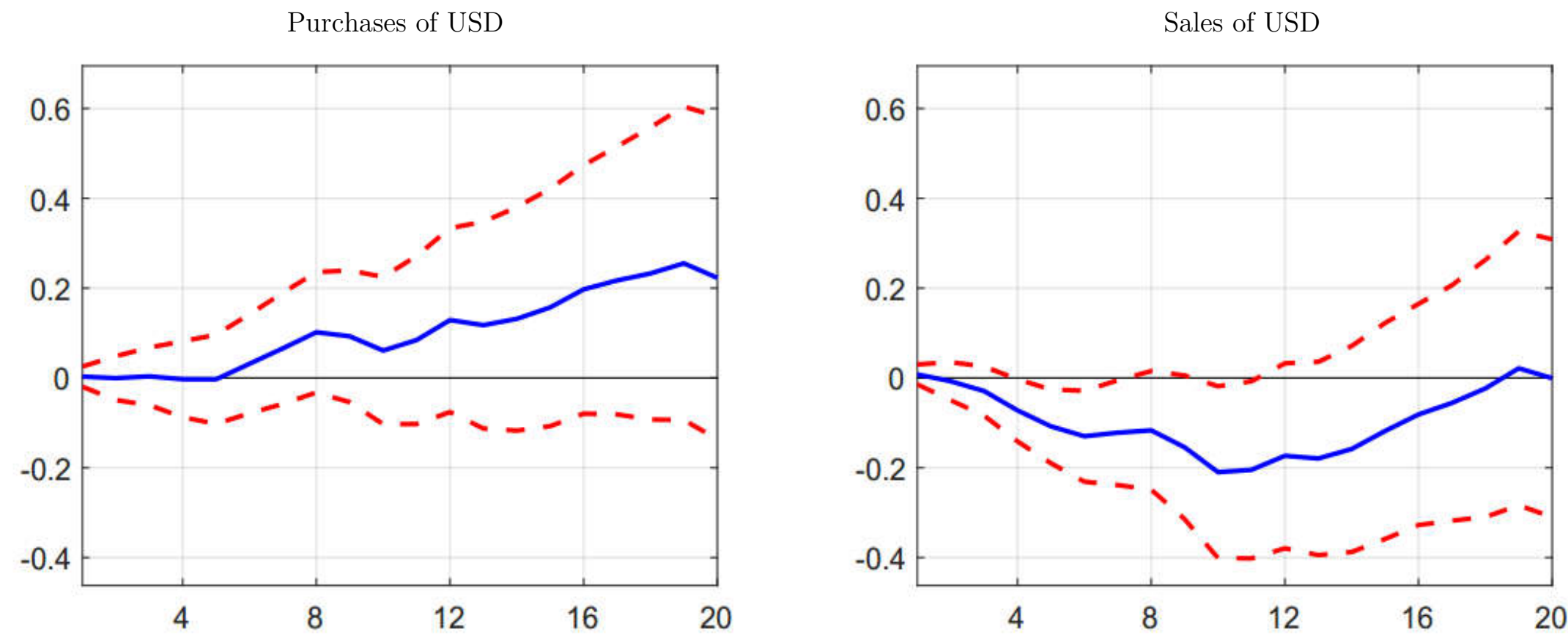

Note: Dashed lines indicate $68 \%$ confidence bands. 


\section{Figure 4}

Estimated effects of intervention on changes in the MNT/USD rate,

January 2012 to December 2015: Main results

Purchases of USD

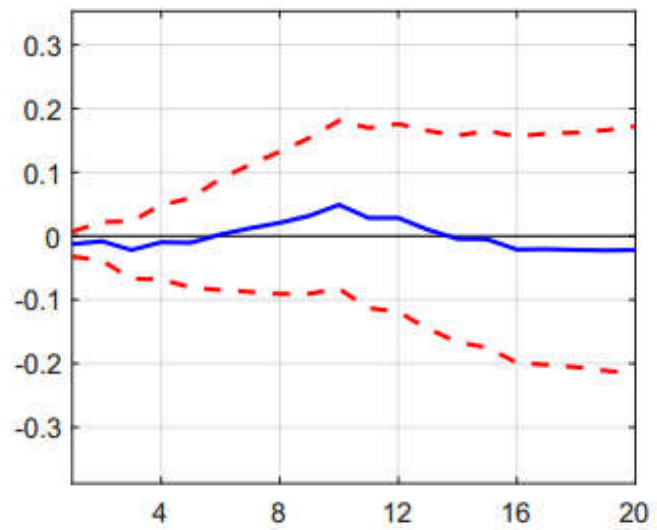

Sales of USD less than or equal to

$$
30 \text { million }
$$

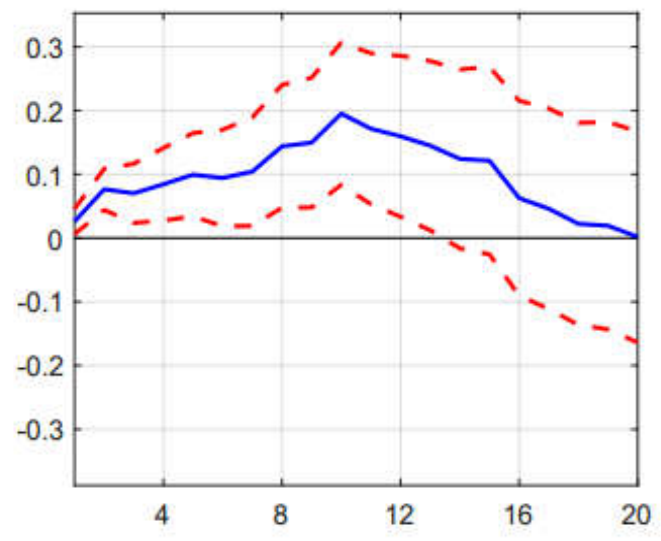

Sales of USD of more than

30 million

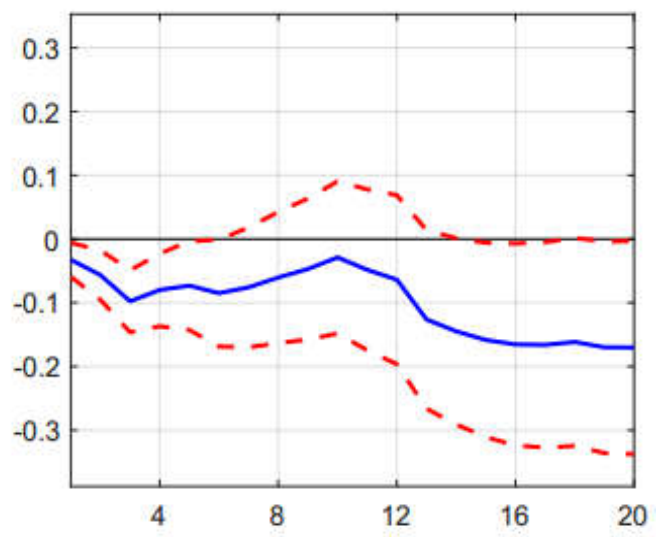

Note: Dashed lines indicate $68 \%$ confidence bands. 


\section{Figure 5}

Estimated effects of intervention on changes in the MNT/USD rate, January 2016 to December 2018: Main results

Purchases of USD

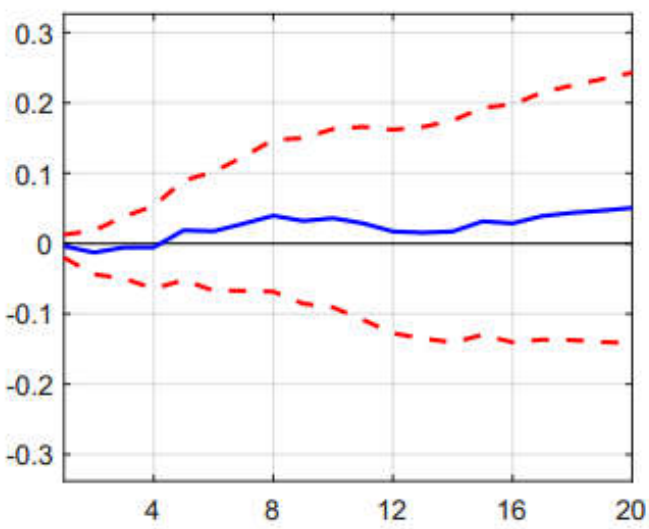

Sales of USD less than or equal to

30 million

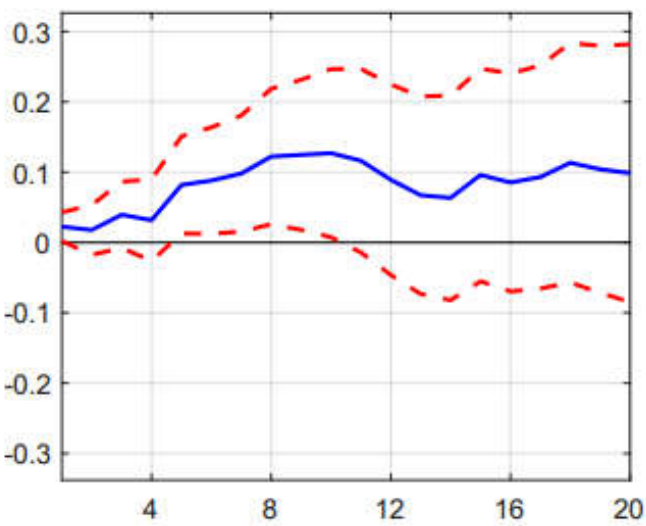

Sales of USD of more than 30 million

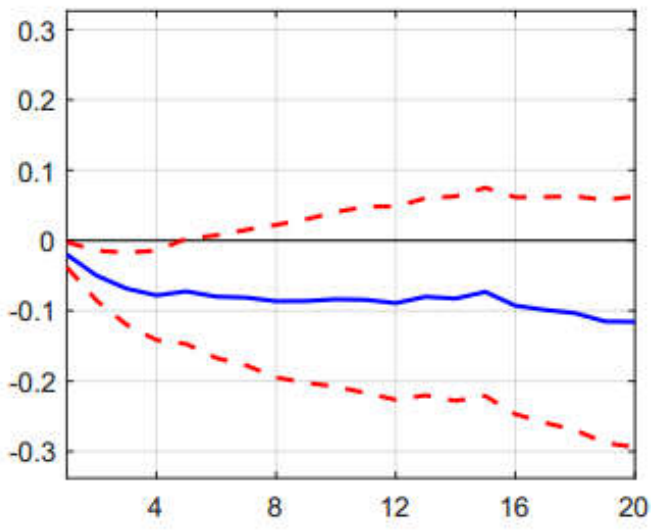

Note: Dashed lines indicate $68 \%$ confidence bands. 


\section{Figure 6}

Estimated effects of intervention on changes in the MNT/USD rate, January 2008 to December 2011: Robustness test (1)
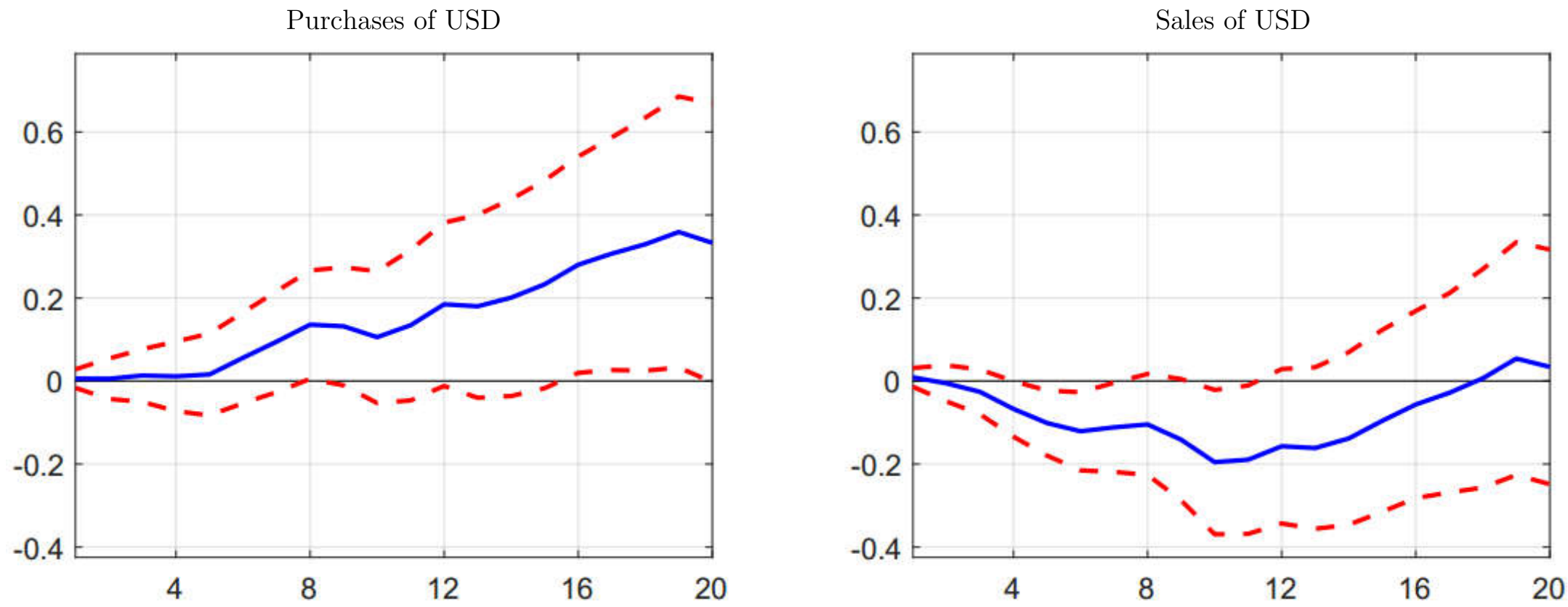

Note: Dashed lines indicate $68 \%$ confidence bands. 


\section{Figure 7}

Estimated effects of intervention on changes in the MNT/USD rate,

January 2012 to December 2015: Robustness test (1)

Purchases of USD

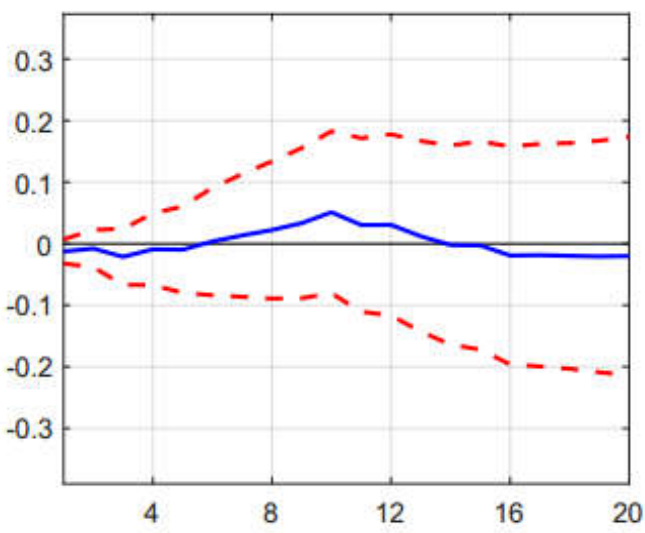

Sales of USD less than or equal to

30 million

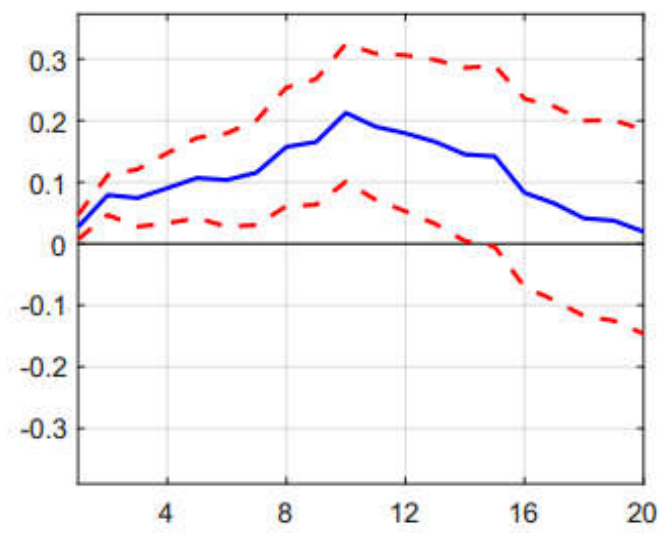

Sales of USD of more than

30 million

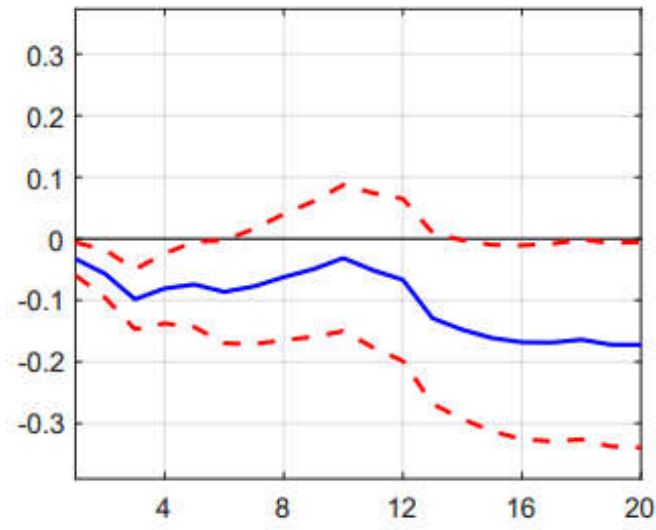

Note: Dashed lines indicate $68 \%$ confidence bands. 


\section{Figure 8}

Estimated effects of intervention on changes in the MNT/USD rate, January 2016 to December 2018: Robustness test (1)

Purchases of USD

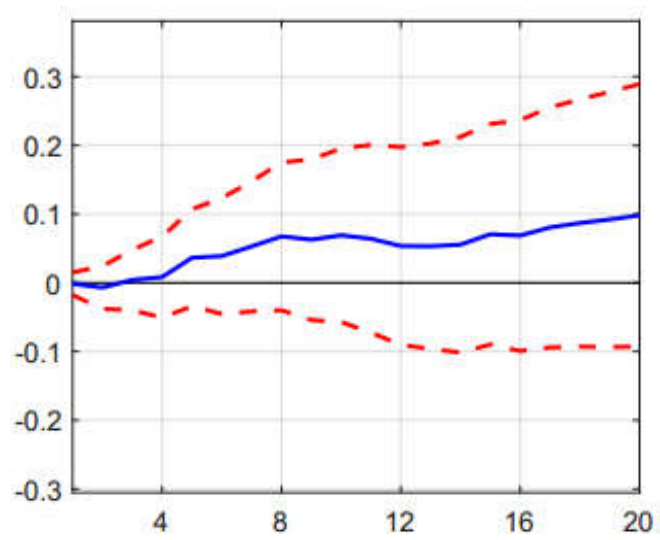

Sales of USD less than or equal to

30 million

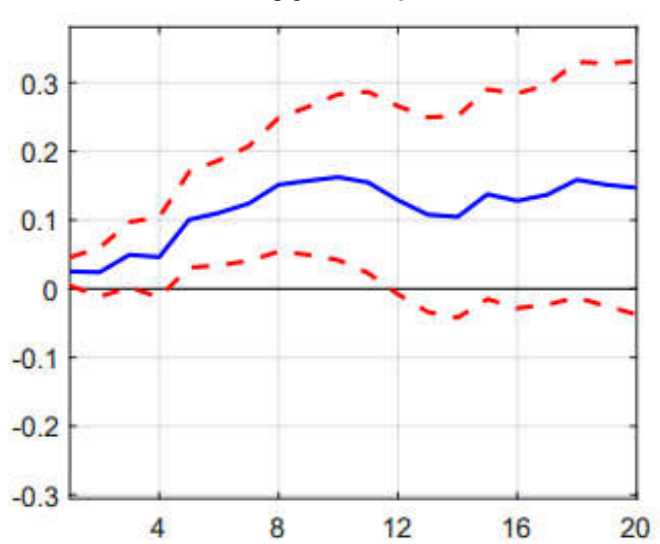

Sales of USD of more than 30 million

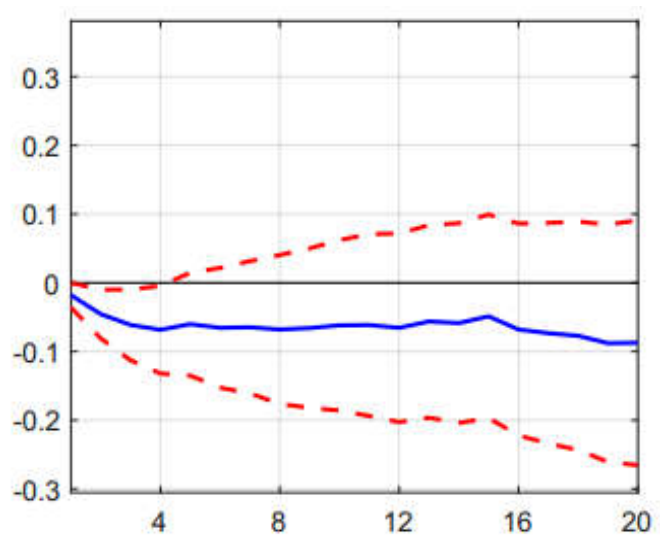

Note: Dashed lines indicate $68 \%$ confidence bands. 
Figure 9

Estimated effects of intervention on changes in the MNT/USD rate, January 2008 to December 2011: Robustness test (2)
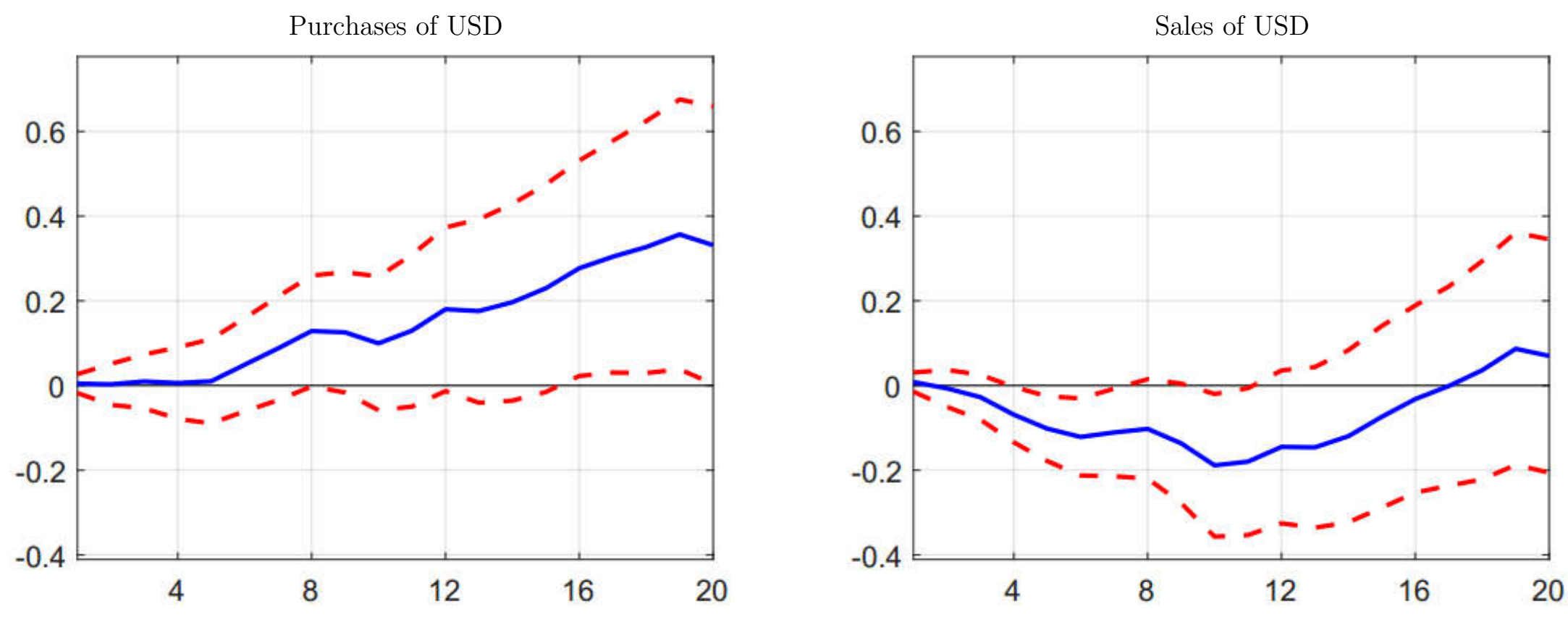

Note: Dashed lines indicate $68 \%$ confidence bands. 
Figure 10

Estimated effects of intervention on changes in the MNT/USD rate,

January 2012 to December 2015: Robustness test (2)

Purchases of USD

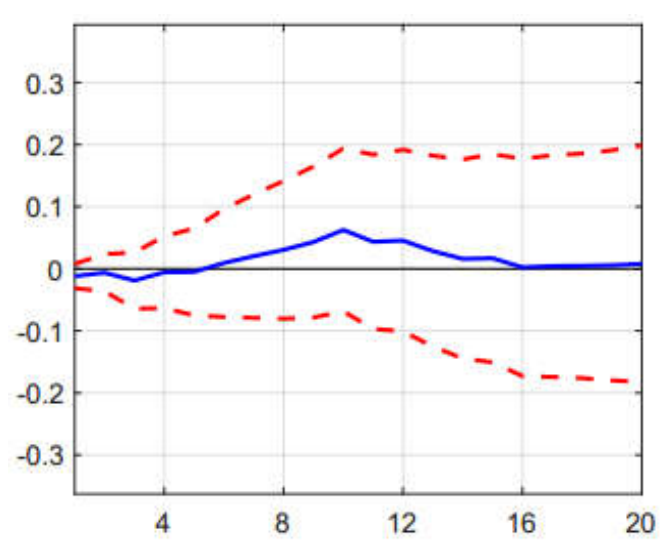

Sales of USD less than or equal to

30 million

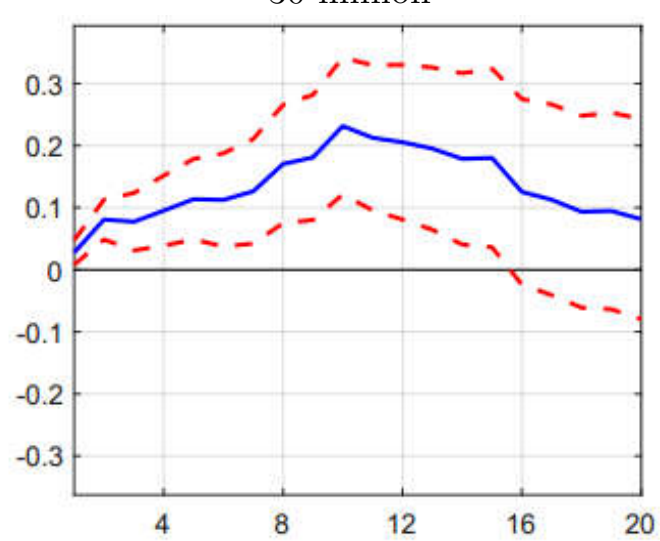

Sales of USD of more than

30 million

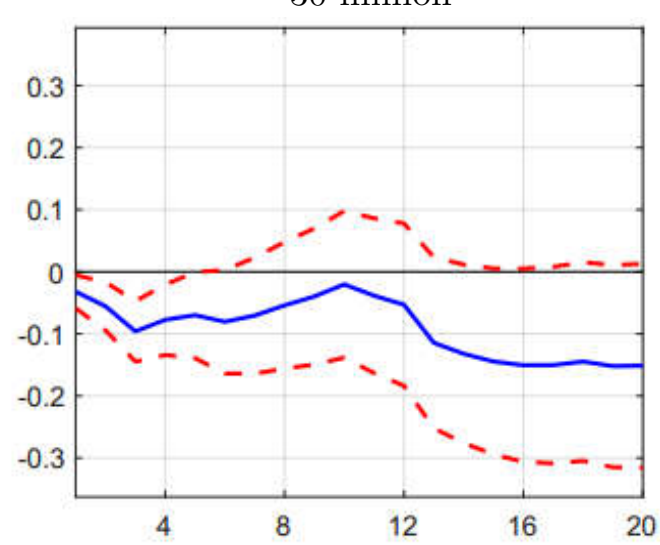

Note: Dashed lines indicate $68 \%$ confidence bands. 
Figure 11

Estimated effects of intervention on changes in the MNT/USD rate,

January 2016 to December 2018: Robustness test (2)

Purchases of USD

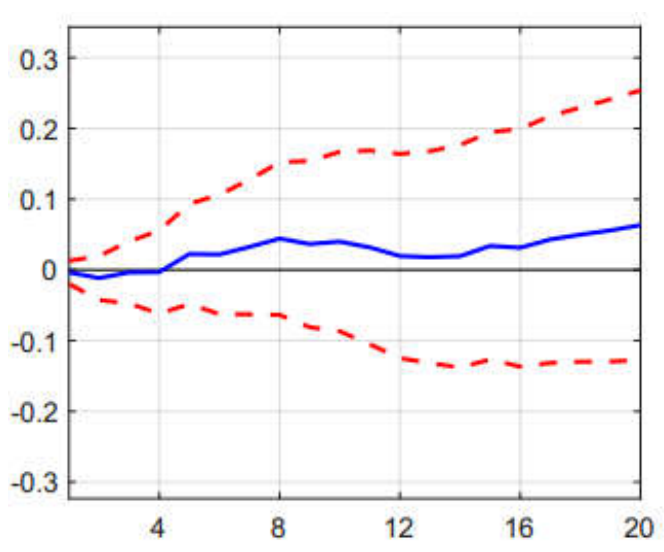

Sales of USD less than or equal to

30 million

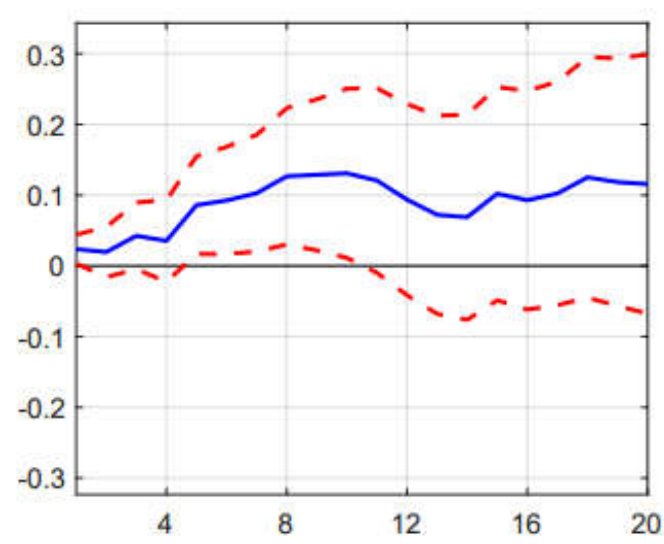

Sales of USD of more than 30 million

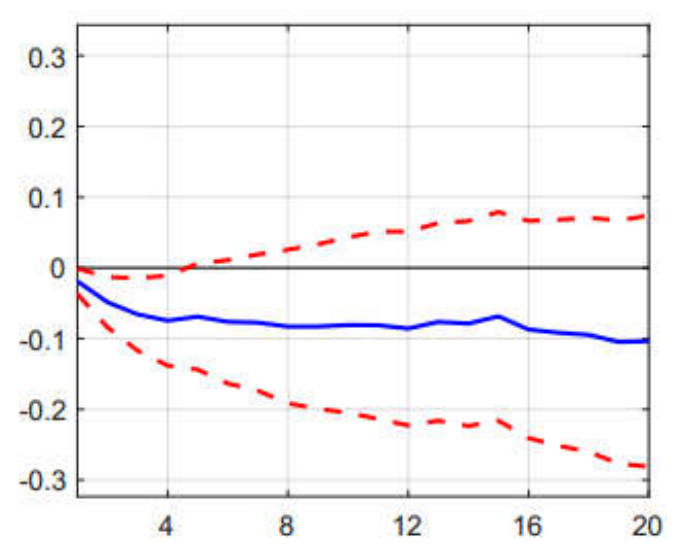

Note: Dashed lines indicate $68 \%$ confidence bands. 
Figure 12

Estimated effects of intervention on changes in the MNT/USD rate, January 2008 to December 2011: Robustness test (3)
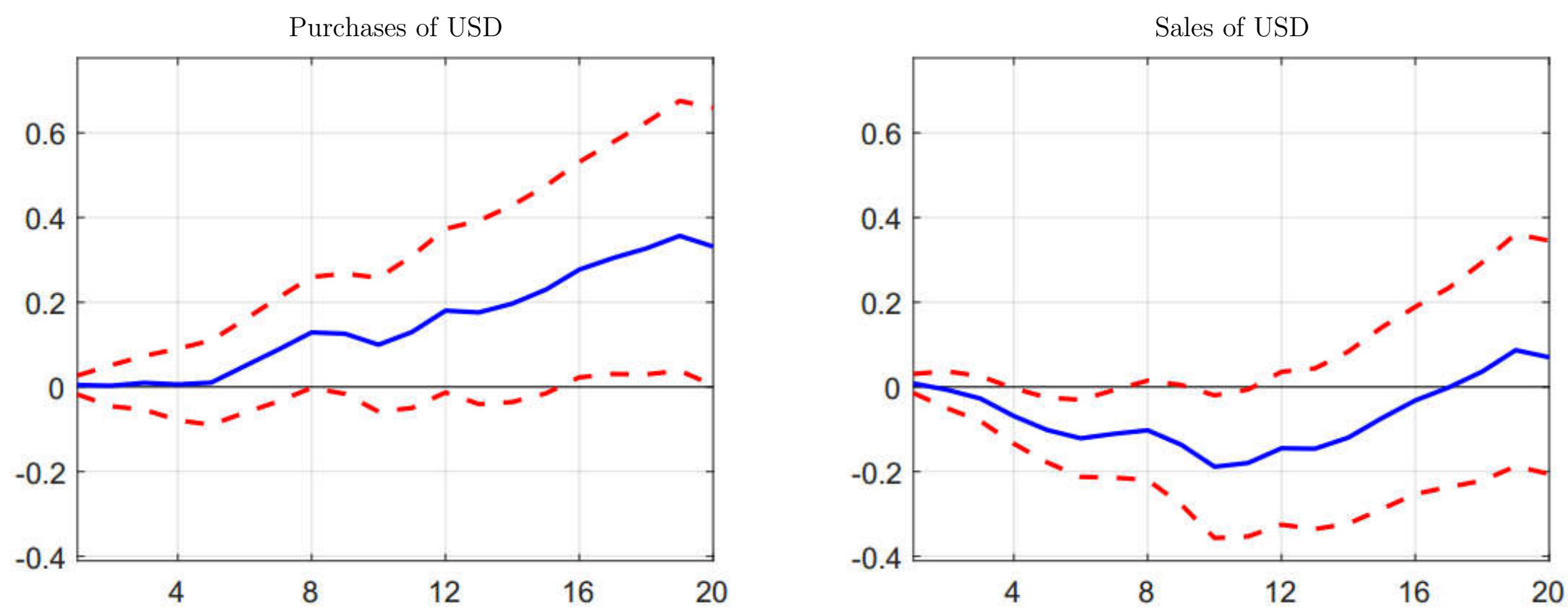

Note: Dashed lines indicate $68 \%$ confidence bands. 
Figure 13

Estimated effects of intervention on changes in the MNT/USD rate,

January 2012 to December 2015: Robustness test (3)

Purchases of USD

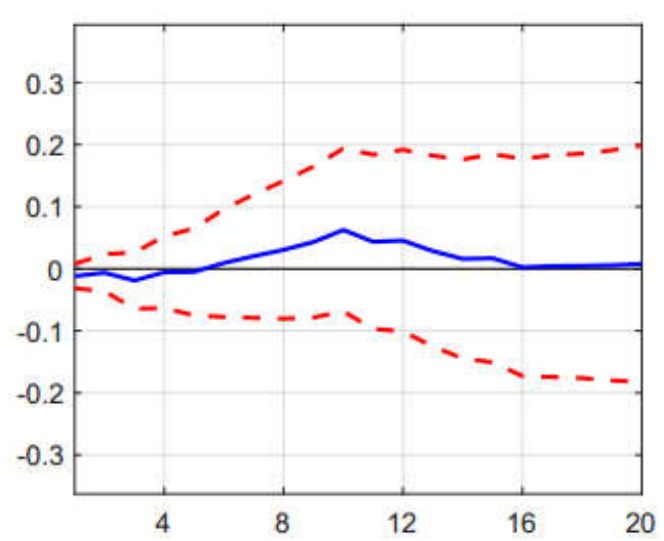

Sales of USD less than or equal to

30 million

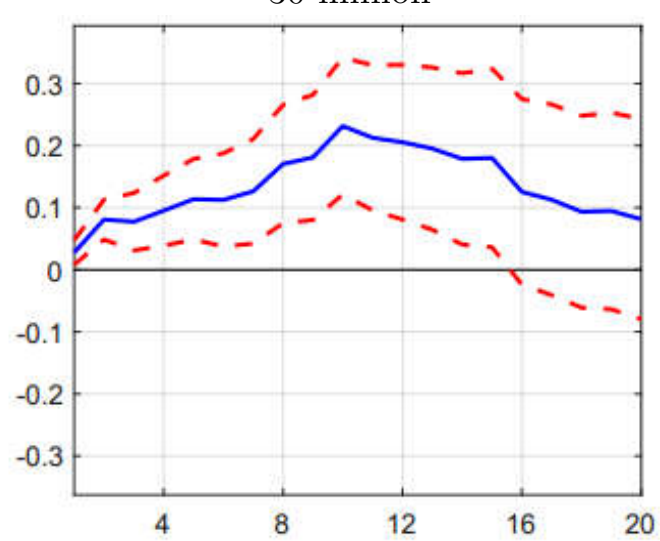

Sales of USD of more than

30 million

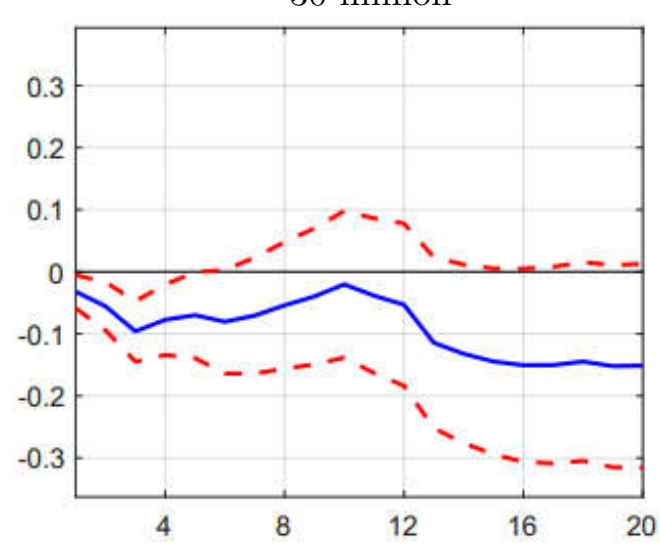

Note: Dashed lines indicate $68 \%$ confidence bands. 
Figure 14

Estimated effects of intervention on changes in the MNT/USD rate, January 2016 to December 2018: Robustness test (3)

\section{Purchases of USD}

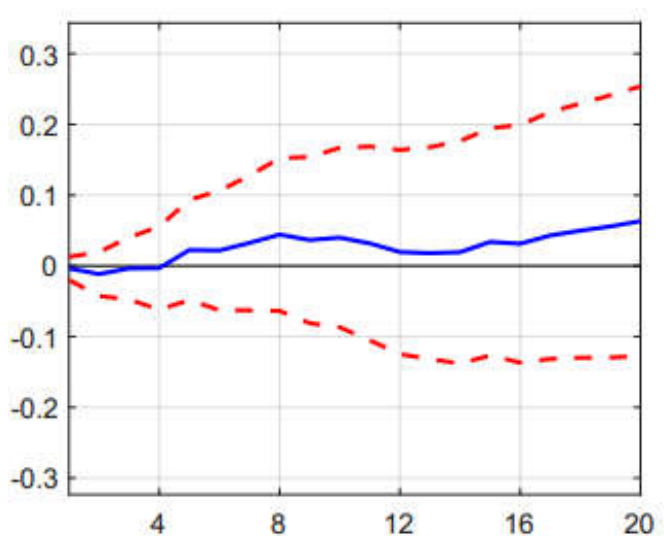

Sales of USD less than or equal to

30 million

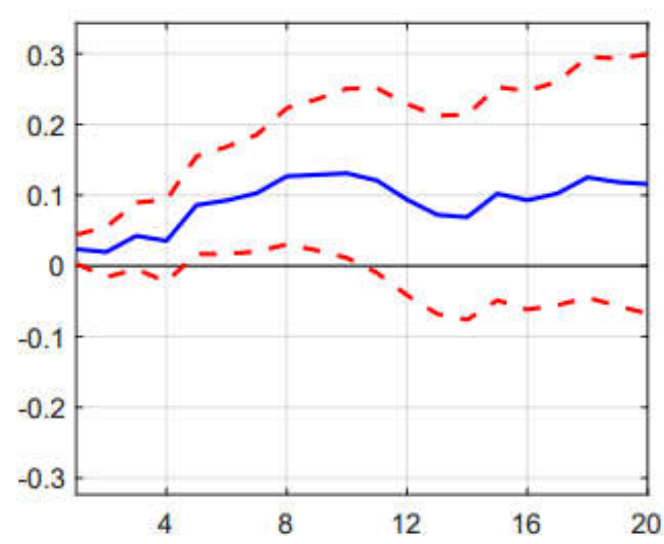

Sales of USD of more than 30 million

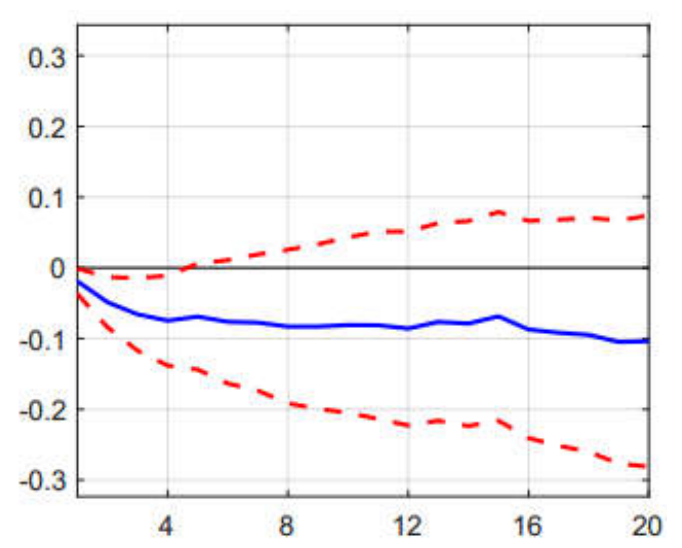

Note: Dashed lines indicate $68 \%$ confidence bands. 
Figure 15

Estimated effects of intervention on changes in the MNT/USD rate, January 2008 to December 2011: Robustness test (4)
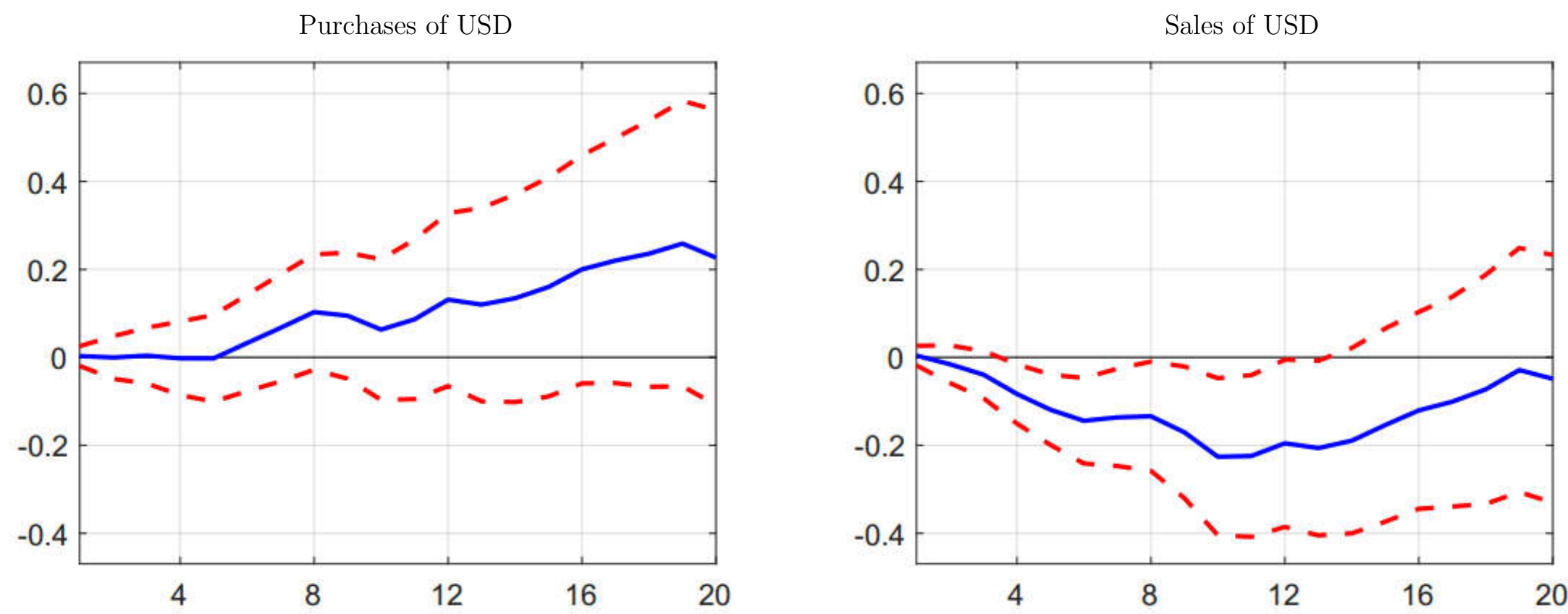

Note: Dashed lines indicate $68 \%$ confidence bands. 
Figure 16

Estimated effects of intervention on changes in the MNT/USD rate, January 2012 to December 2015: Robustness test (4)

Purchases of USD

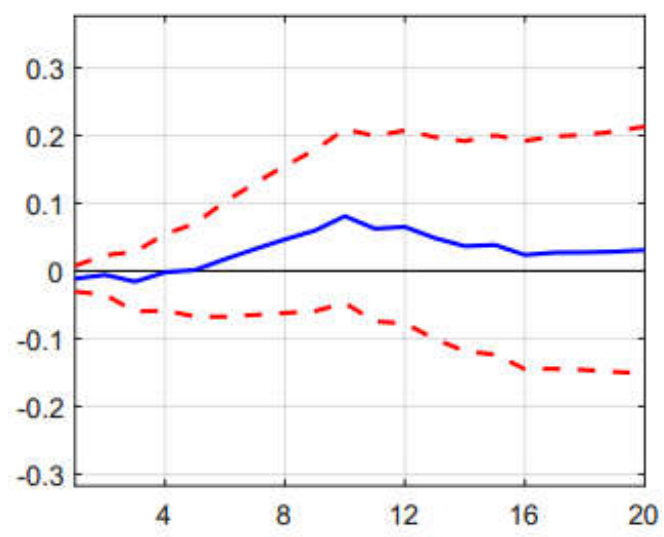

Sales of USD less than or equal to

30 million

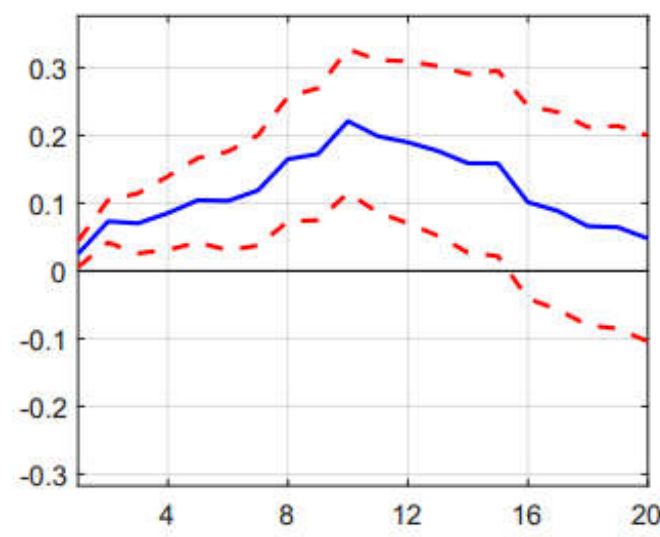

Sales of USD of more than

30 million

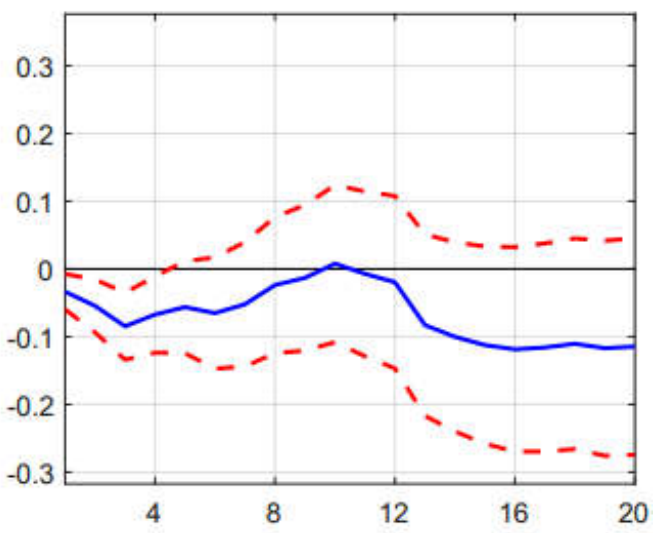

Note: Dashed lines indicate $68 \%$ confidence bands. 
Figure 17

Estimated effects of intervention on changes in the MNT/USD rate,

January 2016 to December 2018: Robustness test (4)

Purchases of USD

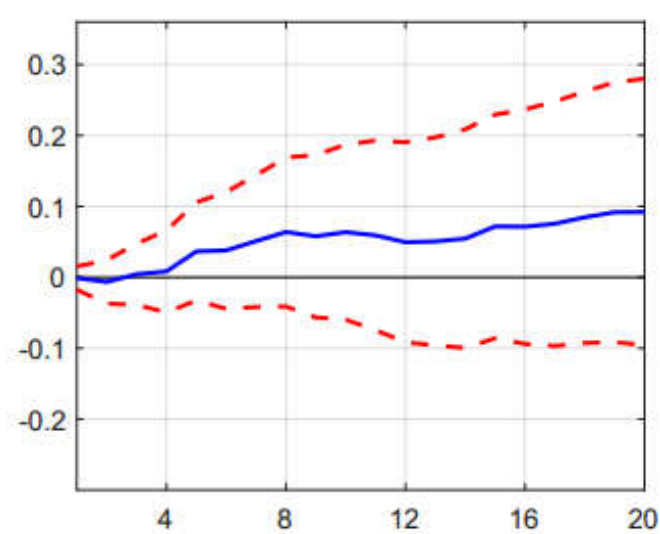

Sales of USD less than or equal to

30 million

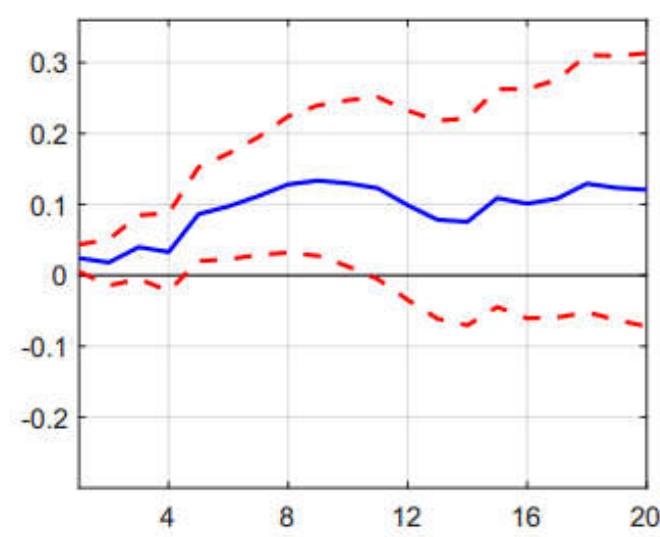

Sales of USD of more than 30 million

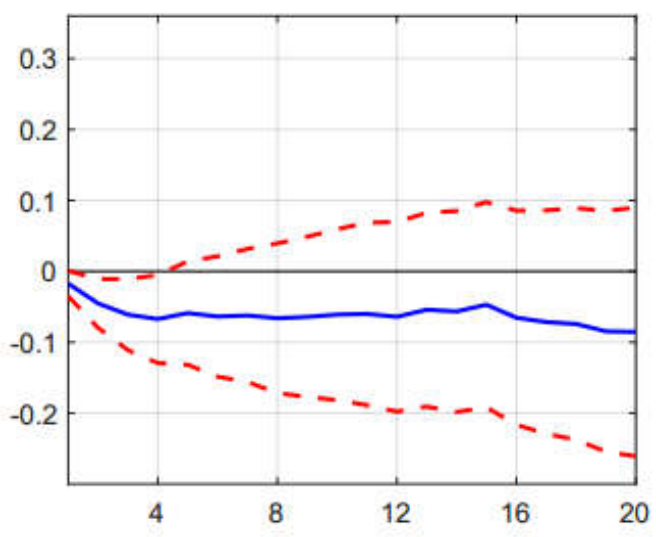

Note: Dashed lines indicate $68 \%$ confidence bands. 